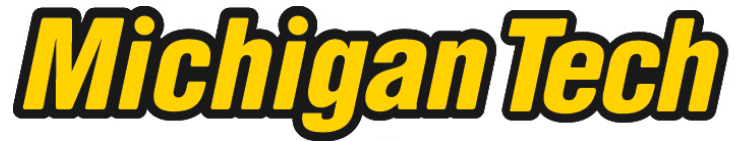 \\ Michigan Technological University Create the Future Digital Commons @ Michigan Tech
}

Dissertations, Master's Theses and Master's Reports - Open

Dissertations, Master's Theses and Master's

Reports

2011

\section{A study of acoustic emission technique for concrete damage detection}

Jun Zhou

Michigan Technological University

Follow this and additional works at: https://digitalcommons.mtu.edu/etds

Copyright 2011 Jun Zhou

\section{Recommended Citation}

Zhou, Jun, "A study of acoustic emission technique for concrete damage detection", Master's report, Michigan Technological University, 2011.

https://doi.org/10.37099/mtu.dc.etds/726 
A Study Of Acoustic Emission Technique For Concrete Damage Detection

By

Jun Zhou

\begin{abstract}
A REPORT
Submitted in partial fulfillment of the requirements for the degree of MASTER OF SCIENCE

Civil Engineering

MICHIGAN TECHNOLOGICAL UNIVERSITY
\end{abstract}

2011

(C) 2011 Jun Zhou 
This report, "A Study of Acoustic Emission Technique for Concrete Damage Detection," is hereby approved in partial fulfillment of the requirements for the Degree of MASTER OF SCIENCE IN CIVIL ENGINEERING.

DEPARTMENT:

Civil and Environmental Engineering

Michigan Technological University

Signatures:

Report Advisor:

Dr. Qingli Dai

Department Chair:

Dr. William Bulliet

Date: 


\section{Table of Contents}

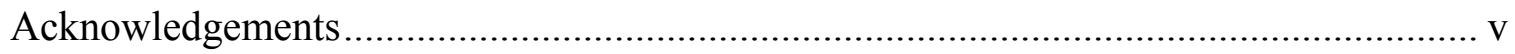

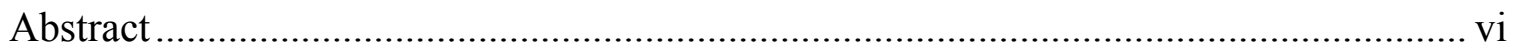

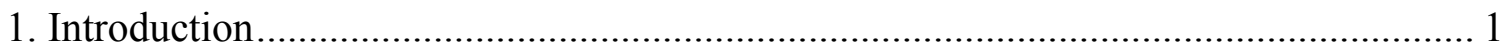

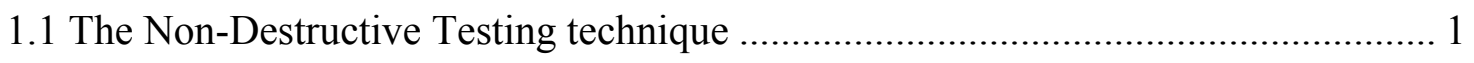

1.2 The relationship between AE technique and other NDT techniques ..................... 1

1.3 The development of the Acoustic Emission (AE) technique ............................... 2

1.4 The applications of AE technique in damage detection ....................................... 4

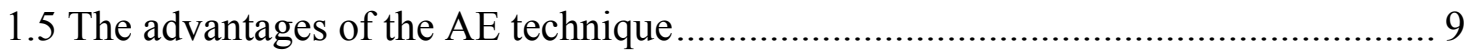

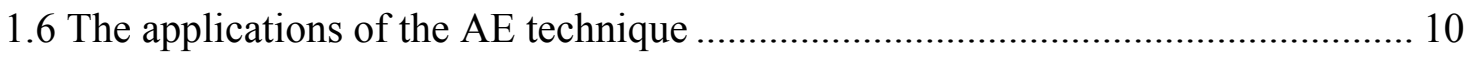

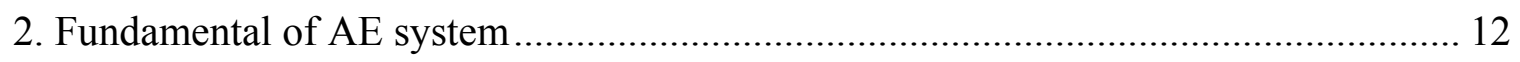

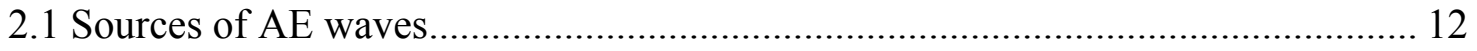

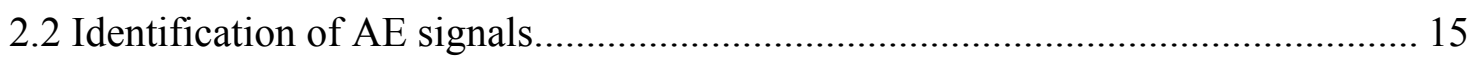

2.3 The Kaiser Effect and Felicity Ratio of AE signals ........................................ 15

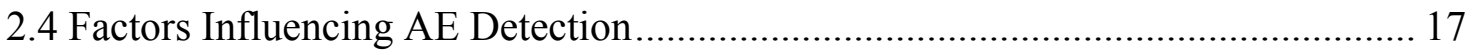

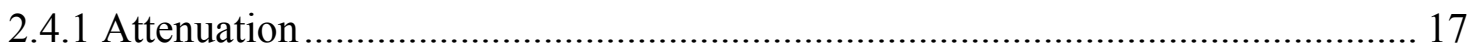

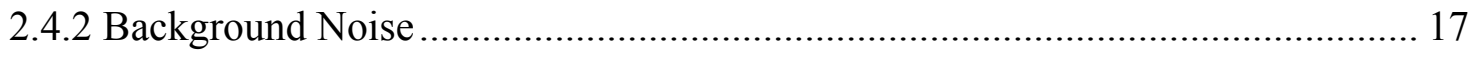

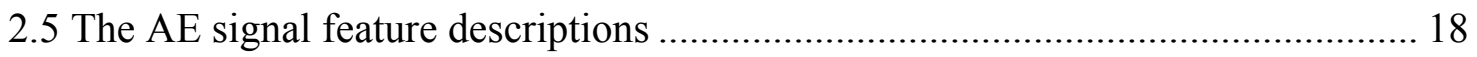

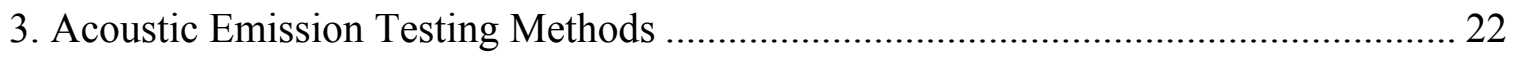

3.1 Parameter-based technique and signal-based technique .................................... 22

3.2 Advantages of parameter-based and signal-based AE techniques ........................ 22

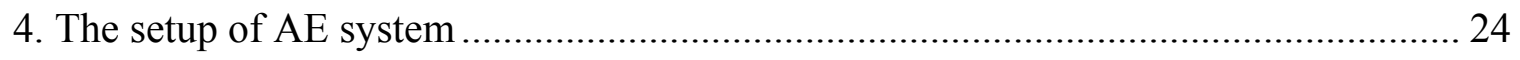

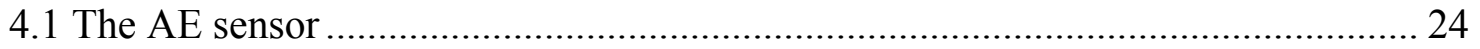

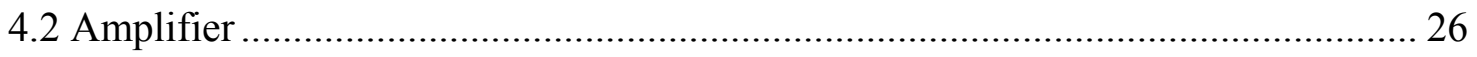

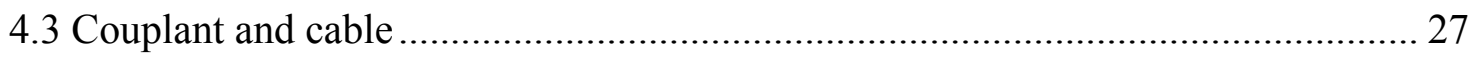

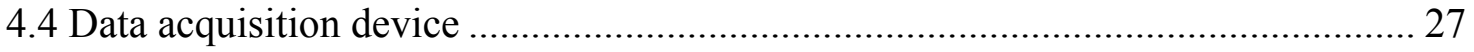




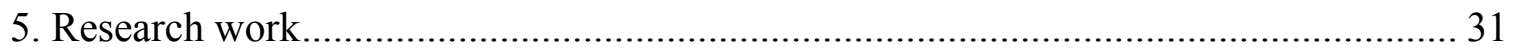

5.1 AE damage detection with pencil lead test .................................................. 31

5.1.1 The pencil lead test setup and procedure................................................ 31

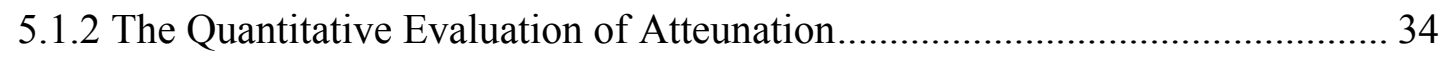

5.2 Three-point single-edge notched beam bending (SEB) test with concrete specimens

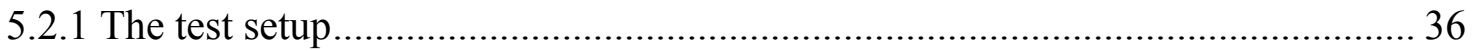

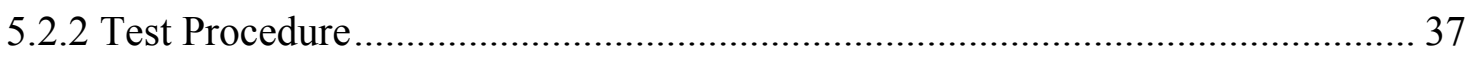

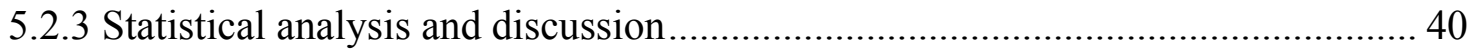

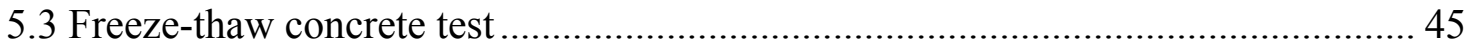

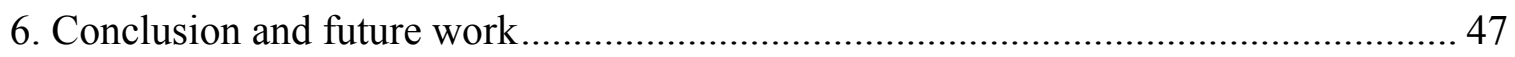

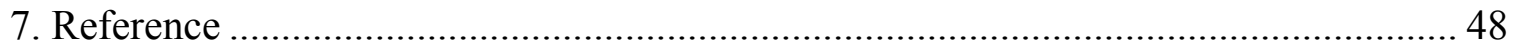




\section{Acknowledgements}

First and foremost, I offer my sincerest gratitude to my advisor, Dr. Qingli (Barbara) Dai, who has supported me along my master study. Without her patience and invaluable advice, this work would not have been possible.

I also would like to express my gratitude to Dr. Yue Li and Dr. Ibrahim Miskioglu who served as my graduate advisory committee and for their help throughout the course of this project.

I wish to thank my parents, my grandparents and my uncle for their perpetual support and faith on me. Without them, my life in the US would not have been so smooth.

I would also appreciate my friend and Ph.D. candidate Kenny $\mathrm{Ng}$ for his valuable assistance in the lab work and suggestion in my report writing. 


\begin{abstract}
The Acoustic emission (AE) technique, as one of non-intrusive and nondestructive evaluation techniques, acquires and analyzes the signals emitting from deformation or fracture of materials/structures under service loading. The AE technique has been successfully applied in damage detection in various materials such as metal, alloy, concrete, polymers and other composite materials. In this study, the AE technique was used for detecting crack behavior within concrete specimens under mechanical and environmental frost loadings. The instrumentations of the AE system used in this study include a low-frequency $\mathrm{AE}$ sensor, a computer-based data acquisition device and a preamplifier linking the $\mathrm{AE}$ sensor and the data acquisition device. The AE system purchased from Mistras Group was used in this study.
\end{abstract}

The AE technique was applied to detect damage with the following laboratory tests: the pencil lead test, the mechanical three-point single-edge notched beam bending (SEB) test, and the freeze-thaw damage test. Firstly, the pencil lead test was conducted to verify the attenuation phenomenon of AE signals through concrete materials. The value of attenuation was also quantified. Also, the obtained signals indicated that this $\mathrm{AE}$ system was properly setup to detect damage in concrete. Secondly, the SEB test with lab-prepared concrete beam was conducted by employing Mechanical Testing System (MTS) and AE system. The cumulative AE events and the measured loading curves, which both used the crack-tip open displacement (CTOD) as the horizontal coordinate, were plotted. It was found that the detected AE events were qualitatively correlated with the global force-displacement behavior of the specimen. The Weibull distribution was 
proposed to quantitatively describe the rupture probability density function. The linear regression analysis was conducted to calibrate the Weibull distribution parameters with detected AE signals and to predict the rupture probability as a function of CTOD for the specimen. Finally, the controlled concrete freeze-thaw cyclic tests were designed and the $\mathrm{AE}$ technique was planned to investigate the internal frost damage process of concrete specimens. 


\section{Introduction}

\subsection{The Non-Destructive Testing technique}

The Nondestructive testing (NDT) techniques were widely applied to detect the internal situation of materials and structures. The link between physics and other applied sciences promote the development of the NDT techniques. When it comes to the classifications of the NDT techniques, they include but are not limited to acoustic emission technique, infrared/thermal testing, visual inspection, penetrating testing, magnetic particle testing, electromagnetic or eddy current testing, radiography, and ultrasonic testing. All of these non-destructive testing approaches can work individually; however, more efficiently if multiple NDTs are employed in the meantime. It is favorable to apply the NDT techniques into heavy industry like power plants, aerospace and aircraft industry, leakage detection of pipelines, damage inspection of dams, construction and maintenance of bridge structure, to name a few (Shiotani, Aggelis et al. 2007). This research principally discussed the utilizations of the Acoustic Emission (AE) technique in concrete damage detection.

\subsection{The relationship between AE technique and other NDT techniques}

The AE technique is distinctive in two main aspects from other traditional NDT techniques (Pollock 1989). Firstly, the AE system is the receiver of signals rather than the emitter like other NDT systems. Secondly, the AE system detects and cares about the internal changes of the materials when service loads are exerted; however, other techniques primarily investigate the discontinuities of the material geometry. The 
summary of the differences in AE technique and other NDT techniques are summarized in Table 1 (Pollock 1989).

Table 1 The comparison between AE technique and other NDT techniques

Acoustic Emission

Detects movement of defects

Require stress

Each loading is unique

More material sensitive

Less geometry-sensitive

Less intrusive on plant/process

Require access only at sensors

Tests whole structure at once

Main problem: noise related
Other methods

Detect geometric form of defects

Do not require stress

Inspection can be repeatable

Less material sensitive

More geometry-sensitive

More intrusive on plant/process

Require access to whole area of inspection

Scan local regions in sequence

Main problem: geometry related

\subsection{The development of the Acoustic Emission (AE) technique}

It is hard to precisely estimate what time people started to use "Acoustic Emission" into their daily life. The earliest application of "Acoustic Emission" can be traced back to $6500 \mathrm{BC}$. The pottery craftsmen listened to audible sounds from ceramics cracking to evaluate quality of their products. Around $3700 \mathrm{BC}$, the acoustic emission phenomenon was witnessed during the process of pure tin being twinned, which was termed as "tin cry." The first written record of acoustic emission was handed down from an Arabian alchemist, who observed sounds emitting from tin and iron in $8^{\text {th }}$ century (Grosse and Ohtsu 2008).

The AE phenomenon mentioned above, are described from literal meaning of "Acoustic Emission," which refers to the audible sounds. Nevertheless, the term "Acoustic emission" used in modern science mostly stands for inaudible sound waves that are ascribed to the elastic deformation or the defect evolution of materials. The early 
research in $\mathrm{AE}$ technique was mainly concentrated on recognized $\mathrm{AE}$ activities and studying the basics of AE phenomenon. The initiation of modern Acoustic Emission Technique (AET) is generally acknowledged to start from the mid $20^{\text {th }}$ century with the issue of Kaiser's article (Ohtsu 1995). After that B.H Schofield repeated this test and firstly named this sound emitting phenomenon as "Acoustic Emission" in his publication. He convinced that the volumetric change rather than the surface reaction was the source of AE.

After that, AE technique was complemented by the reform of computerized testing instrumentations and evolving during the next several decades. Nowadays, AE technique is being extensively applied into detecting structure flaws, inspecting weld quality, detecting loose particles, aerospace and aircraft industry, detecting and locating leakage, manufacturing FRP (fiber-reinforced plastic) tanks and pressure vessels, bridges, and so on. Thus, acoustic emission technique provides supplementary information about the service condition of the structure, which is especially meaningful to aging in-service structures. So far, the procedures of implementing the $\mathrm{AE}$ technique has already been documented and published by the organizations like the American Society of Mechanical Engineers (ASME), the American Society for Testing and Materials (ASTM). Besides, International Organization for Standardization, International Organization for Standardization (ISO), and Japanese Institute for Standardization (JIS) also published relevant standards to elaborate the procedures of the $\mathrm{AE}$ testing. 


\subsection{The applications of $\mathrm{AE}$ technique in damage detection}

The thriving construction industry makes concrete the most consumed construction material in the world (Nair and Cai 2010). However, the concrete structures deteriorate with time elapsing and need be repaired after the damage (Uddin, Shigeishi et al. 2006; Carpinteri, Lacidogna et al. 2007; Granger, Loukili et al. 2007). The long-term health status of concrete structures especially the ones under rigid circumstances are of vital importance to human lives and properties. By virtue of the $\mathrm{AE}$ technique, it provides researchers insight into a better understanding of concrete material under various loadings like flexural loading, cyclic loading, impact loading, freezing-thawing loading, and fatigue effect; and even under chemical influence like corrosion (Morton, Harrington et al. 1973; Pollock 1989; Berkovits and Fang 1995; Labuz, Cattaneo et al. 2001).

When concrete structures become aging, they will be inevitably undermined by the surrounding environment, one of which is freezing-and thawing damage $(\mathrm{Li}$, Sun et al. 2011). The AE technique is applied to monitor internal failure of this kind of quasibrittle material (Suzuki, Ogata et al. 2010).

By applying the $\mathrm{AE}$ technique, it is possible to classify the types of cracking (Farid Uddin, Numata et al. 2004; Grosse and Finck 2006; Ohno and Ohtsu 2010). The crack classification methods were introduced two crack classification methods by analyzing parameter of AE signals like hits, count, duration time, amplitude, energy, and rise time. Besides, concrete failure tests are carried out to compare these two methods. Moreover two parameters in the parameter-based method: RA value (the ratio of rise time 
to maximum amplitude), and average frequency (AE counts to duration). Both of them can be applied to categorize concrete crack into tensile mode and shear mode. In the signal-based method, arrival time and amplitude of the first motion are two main study objectives. According to the results analyzed by the parameter-based and the signalbased method, disagreement was found. One possible explanation might be that parameter-based method adopts all AE signals; however, signal-based method only analyzes $\mathrm{AE}$ events. In the four-point bending test of the reinforced concrete beam, the diagonal-shear fracture is dominant failure mode. It exhibits agreement between the parameter-based method and the signal-based method. In the hydrostatic expansion test, similar results were found with these methods.

The $\mathrm{AE}$ technique is also used to investigate the performance of concrete slab with and without reinforcing fiber (Soulioti, Barkoula et al. 2009). Four-point beam bending tests were implemented to investigate the cracking behavior of the concrete slabs with different fiber contents. Acoustic emission technique was also employed to analyze the transition of failure modes of concrete specimens. As the test results implied, the increase in fiber content from none to $0.5 \%$ will defer crack propagation. The debonding between steel fiber and concrete matrix will cause more AE activities. Moreover, it discussed average frequency and RA value to interpret the alternation of cracking mode between shear mode to tensile mode. It was also feasible to explain the mechanism how cracks propagate within the reinforced concrete.

In Labuz's work (Labuz, Cattaneo et al. 2001), three mechanical testing, which are diametric compression test, flexural test, and indentation test, were implemented on quasi-brittle materials. By observing the internal defects detected by AE system, intrinsic 
process zone was defined when specimens were loaded to peak stress. It was found that the length of the zone is similar even in the specimens with different sizes.

Fiber reinforced concrete (FRC) slabs with different fiber content were tested under four-point bending test in Soulioti's work (Soulioti, Barkoula et al. 2009), which aimed at exploring the correlation between occurrence of $\mathrm{AE}$ signals and material properties. It was found that detected $\mathrm{AE}$ activities intensified with the increase of fiber content. In addition, there is a failure mode transition from tensile fracture to shear fracture observed in concrete slabs with increasing fiber content. So, the AE technique supplies better understanding on designing sustainable structure and identifying the damage condition.

The fatigue crack damage of T-girder test was implemented in Robert's research (Roberts and Talebzadeh 2003). The results showed AE count rates correlated well with cracking propagation rate. Based on this analytical method, remaining life of steel under fatigue loading can be estimated.

Shigeishi's research (Shigeishi, Colombo et al. 2001) concentrated on the health diagnosis of masonry and reinforced concrete arch bridges built long time ago. The AE technique was applied and proven to be feasible in inspecting crack growth in the bridges.

Choudbury and Tandon (Choudhury and Tandon 2000) evaluated the applicability of the $\mathrm{AE}$ technique in detecting the defects in inner face and roller bearing. It was found that the parameters of amplitude and counts in smaller size specimen were associated with the occurrence of defects. 
Chen and Liu (Chen and Liu 2004) investigated the influence of notch depth and fiber content on the features of AE signals when implementing three-point concrete beam bending test. It was observed that with the increase of notch depth, the peak of $\mathrm{AE}$ signals postponed and the amplitude of the AE signals decreased. Statistics analysis showed the agreement between AE signal distribution and the Weibull damage function.

Prosser (Prosser 1996) introduced a promising AE technique named Model AE, which characterized by its high performance in noise control. This technique benefits from the rapid development of testing instrumentations. Model AE technique has been proven to be practicable in identifying the defect propagation in composite materials. However, high attenuation and complex geometrical features are still factors need to be better understood.

In Zhang's research (Wei Zhang 2008), the wide band sensor was employed to investigate the structure experiencing severe defects. During the mechanical testing, three phases of cracking development in beam were studied. It was concluded that the frequency of AE signals varied and high frequency signals that exceed $1 \mathrm{MHz}$ were also observed.

Weiler (Bernd Weiler 1997) studied the workability of AE technique in concrete under three loading scenarios, which were three-point bending, axial tension and compression. In the results analysis, the locations of $\mathrm{AE}$ sensors and the nature of properties like heterogeneity of concrete, high attenuation, different geometrical dimensions were taken into account. 
Shield's work (Shield 1997) applied three-point beam bending test to support the correlation between $\mathrm{AE}$ event rate and crack occurrence. Besides, the existence of Kaiser Effect has been validated.

Golaski's paper (Leszek Golaski 2002) reported in-situ applications of AE technique in monitoring on realistic reinforced concrete, prestressed concrete, and concrete-steel bridges. Through the series of testing, it was concluded that the specific bridge inspecting procedure should be adopted into particular testing project.

Ohno and Ohtsu's research (Ohno and Ohtsu 2010) introduced two crack classification methods, which are parameter-based method and signal-based method. Three concrete failure tests were carried out to compare these two methods and it showed an agreement between them.

Some research works (Ohtsu and Watanabe ; Suzuki and Ohtsu 2004) aimed at quantitatively evaluating the damage level of the concrete structure under uniaxial compression by using rate process analysis. The result indicated that rate process analysis was able to assess the concrete damage without knowing the initial properties of concrete like Young's Modulus.

Suzuli's work (Suzuki, Ogata et al. 2010) focused on the frost-caused damage. The degree of damage was estimated by rate-process analysis and damage mechanics. Term Durability index proposed in this paper can be compared with the results from helical computerized tomography (CT) scan to estimate the properties decrease (damage increment) within concrete. The relationship was established between CT values and the durability index. 
In Ranjith's work (Ranjith, Jasinge et al. 2008), the AE technique was applied in the research of investigating the influence of moisture content and displacement rate on the properties of underground concrete structures.

In Otsuka's work (Otsuka and Date 2000), 3-D AE technique was applied combining with X-ray to detect the fracture process zone in concrete with notch. It was found that the $\mathrm{AE}$ event concentrated at notch tip together with the accumulation of microcrack observed at the same location. The expansion of fracture zone was caused by the increase of maximum aggregate size or specimen size.

\subsection{The advantages of the $\mathrm{AE}$ technique}

The excellence of $\mathrm{AE}$ technique enables conducting overall structural real-time monitoring without affecting the workability of the objects (Pollock 1989; Ohtsu 1995). When applying AE technique on large scale of structures, it only requires limited number of sensors placed separately on the surface of the structure to perform inspection. It reduced workload and complexity of testing when the objects have no easy accessibilities. It efficiently balances the relationship between financial expense and time. The ease of testing system setup makes rapid monitoring possible. By employing enough sensors and data processing devices, the defects could be localized and quantified with controlled errors. According to the testing requirement, detection work can be more accurate and time-saving when $\mathrm{AE}$ technique cooperated with other destructive or nondestructive testing approaches. In the practical testing, technicians often conduct $\mathrm{AE}$ technique for global inspection to localize the flaws, and then other NDT approaches are applied to accumulate more information from the formed defects. 


\subsection{The applications of the $\mathrm{AE}$ technique}

As a natural phenomenon, acoustic emission takes place in broad ranges of existing materials. Therefore, there are three main regions that $\mathrm{AE}$ technique serves as powerful tool (Pollock 1989). Generally speaking, AE technique can always be a candidate when testing is associated with deformation. First, AE technique is a useful support in laboratory testing. Collected AE signals can provide researchers better understanding of the properties of the test objects. Second, in manufacturing industry, AE technique provides assistance in quality control such as welding quality and brazed joints, thermo-compression bonding, shaft straightening, and punch press operating. Third, AE technique facilitates the integrity inspection of in-service structures including storage tank, pressure vessels, aerospace and aircraft industry, dam, power plant, bridge, bucket truck, to name a few (shown in Figure 1). Besides, due to the high sensitivity of AE system, the instrumentations can receive not only defect-related deformation but also behaviors like friction, impact, corrosion, liquid flow, and so on. Hence, AE is also a powerful tool in loose particle detection, metal corrosion, pipeline leakage. 

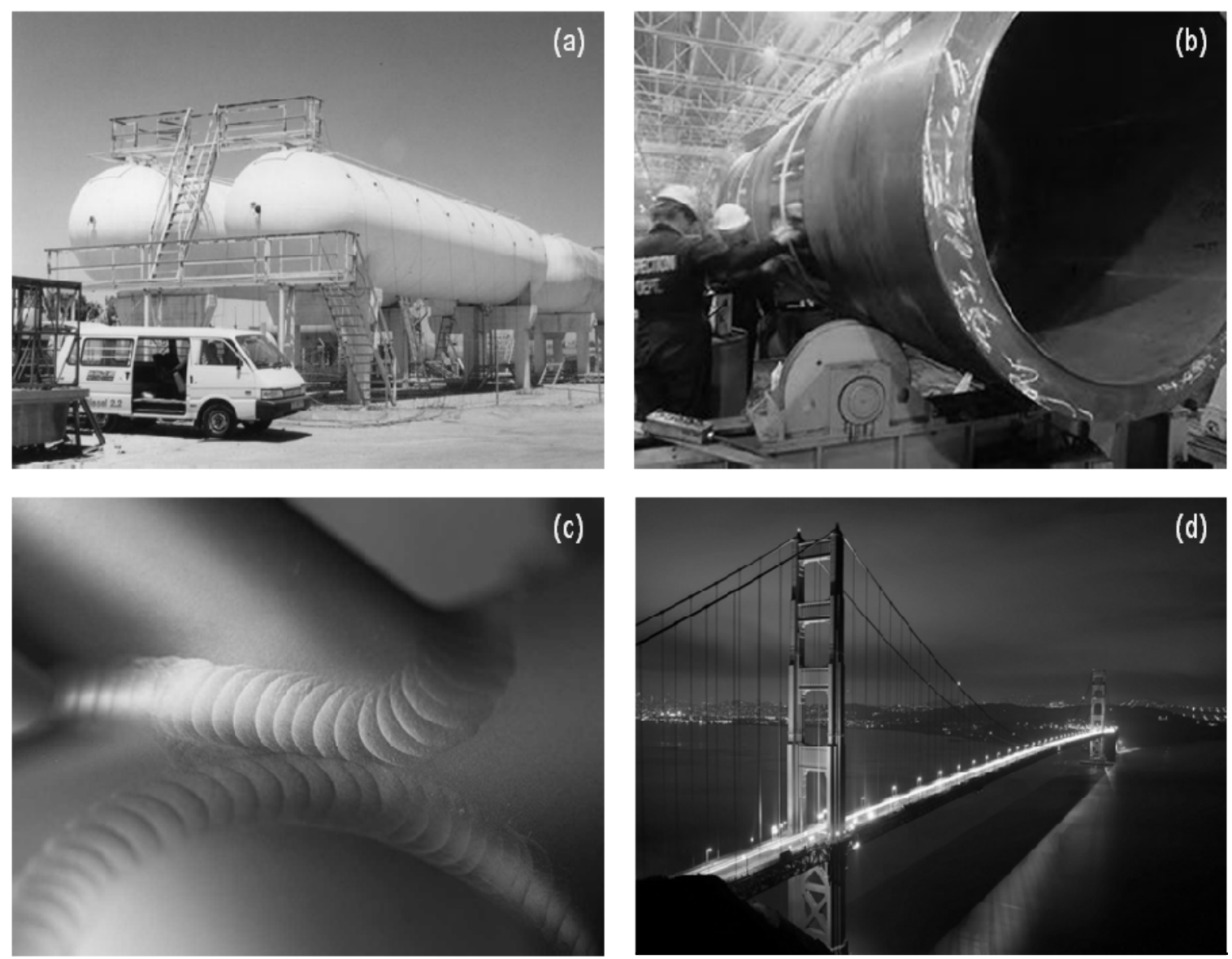

Figure 1 The application of Acoustic Emission technique: (a) pressure vessel; (b) leakage of pipeline inspection; (c) weld quality inspection; (d) bridge integrity monitoring (www.ndt.org) 


\section{Fundamental of AE system}

\subsection{Sources of AE waves}

The main sources of AE waves can be attributed to stress-provoked deformation, for example, the formation of micro-crack and plastic deformation, and crack propagation. A wide range of materials exhibit $\mathrm{AE}$ activities when under stress. When variable stress is applied on the materials, the deformation is generated from the extent of microscopic view. Consequently, released energy emits as the form of elastic waves which excites an AE sensor mounting on the surface of the structures. Accordingly, these waves are recognized as $\mathrm{AE}$ signals. In the nature world, the resources of $\mathrm{AE}$ signals are extensive such as vibrations of earthquakes, corrosions of stones and rocks, and even wind load (Carpinteri and Lacidogna 2007). In practical applications, when structures or materials under tested such as composite and polymers are subjected to external loadings, an $\mathrm{AE}$ sensor is capable of detecting and transforming $\mathrm{AE}$ waves into electrical signals. Then, these signals are conveyed into data acquisition devices for post processing procedure.

AE waves are comprised of $P$ wave and $S$ waves, which radiate variously within the materials due to the different properties (Pollock 1989). P waves are also called longitudinal waves, primary waves that could generate from earthquakes. Besides, P waves exhibit the highest transmitting velocity and internal compression/rarefaction mechanism. S waves are also named shear waves. The moving direction is perpendicular to the wave propagation. The materials characterizing as brittleness and heterogeneity are inclined to be more emissive and the materials that exhibit high ductility response to 
the stress with lower acoustic emission. In Figure 3, acoustic emission occurs coupling with the decrease of signal velocity, however with the increase of Poisson' ratio and axial displacement (Ohtsu 1995). According to the shape of AE waveforms, AE signals are classified into two main types: the burst type and the continuous type, which are shown in Figure 4 and Figure 5. The burst acoustic emission is referred to single event taking place in the material. On the other hand, continuous acoustic emission is result from the overlaying of large quantity of $\mathrm{AE}$ signals. Thus, individual AE signal cannot be discriminated. Generally speaking, burst AE signals often exist in brittle materials such as concrete; besides, the continuous $\mathrm{AE}$ signals are for ductile materials like steel and alloys. Due to the properties of the two AE signals, the analytical methodologies are different. Most research works lay emphasis on the continuous acoustic emission, which is more meaningful to practical applications. For continuous acoustic emission, root mean square (RMS) and Average Signal Level (ASL) are of interest to researchers.

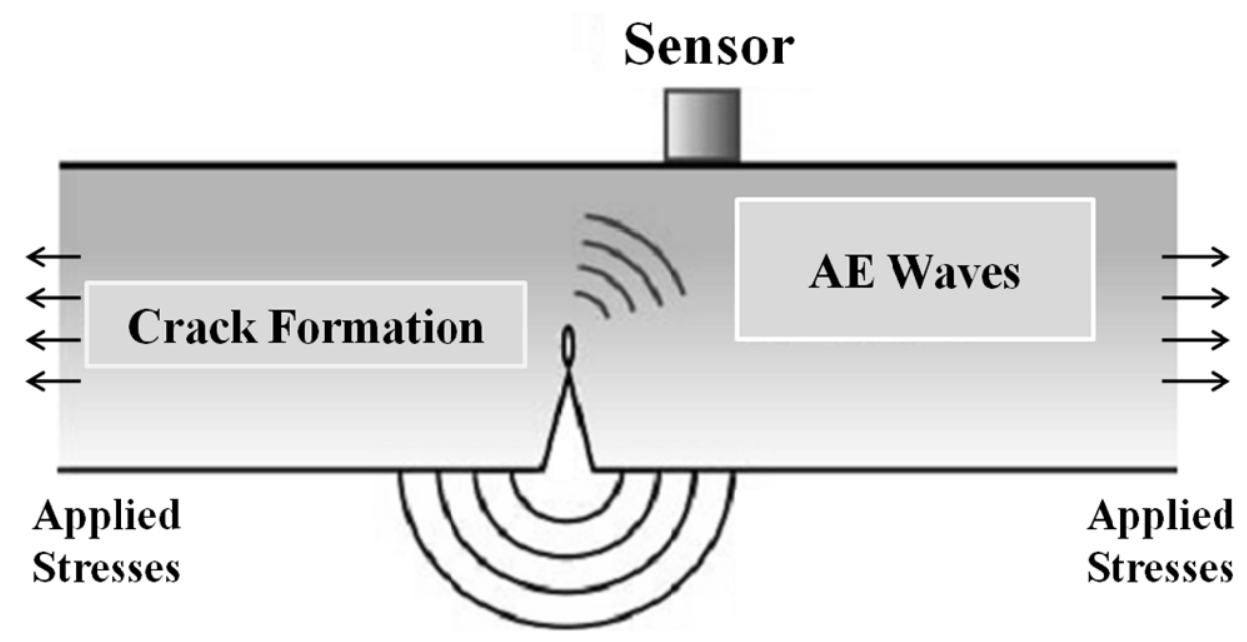

Figure 2 Detection of AE signals (by author) 


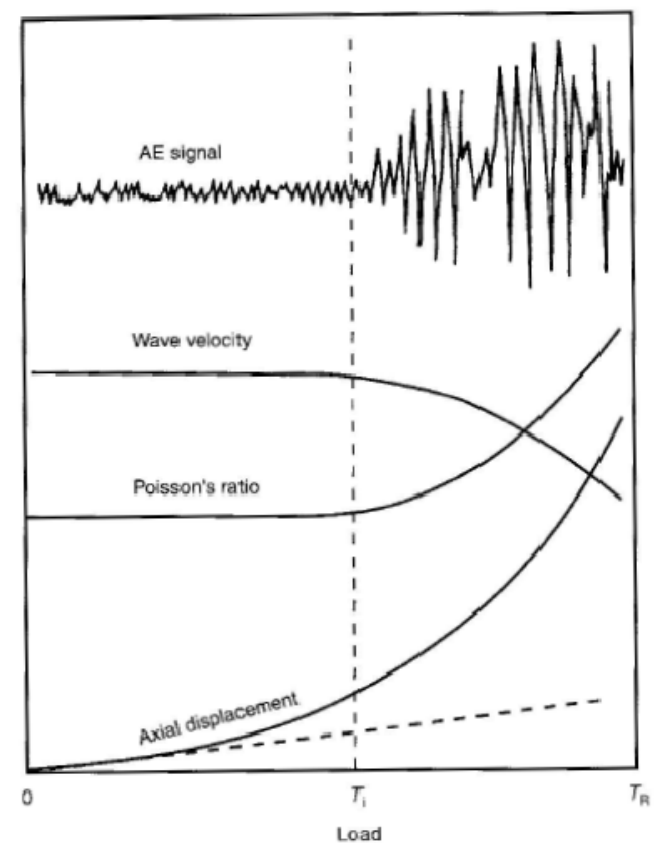

Figure 3 Mechanical properties of concrete under compression (Ohtsu 1995)

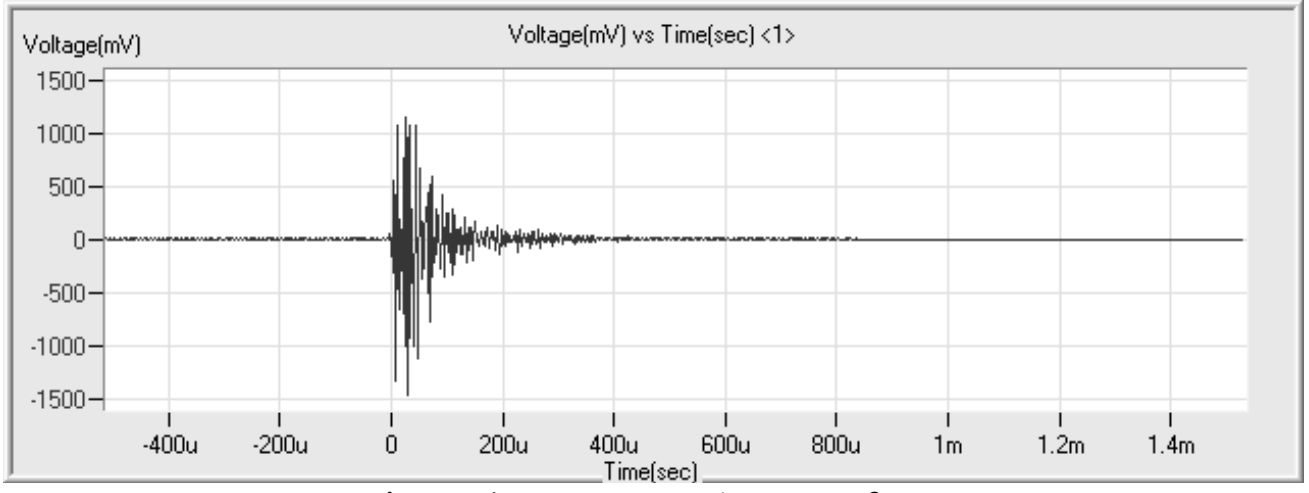

Figure 4 Burst-type AE waveform

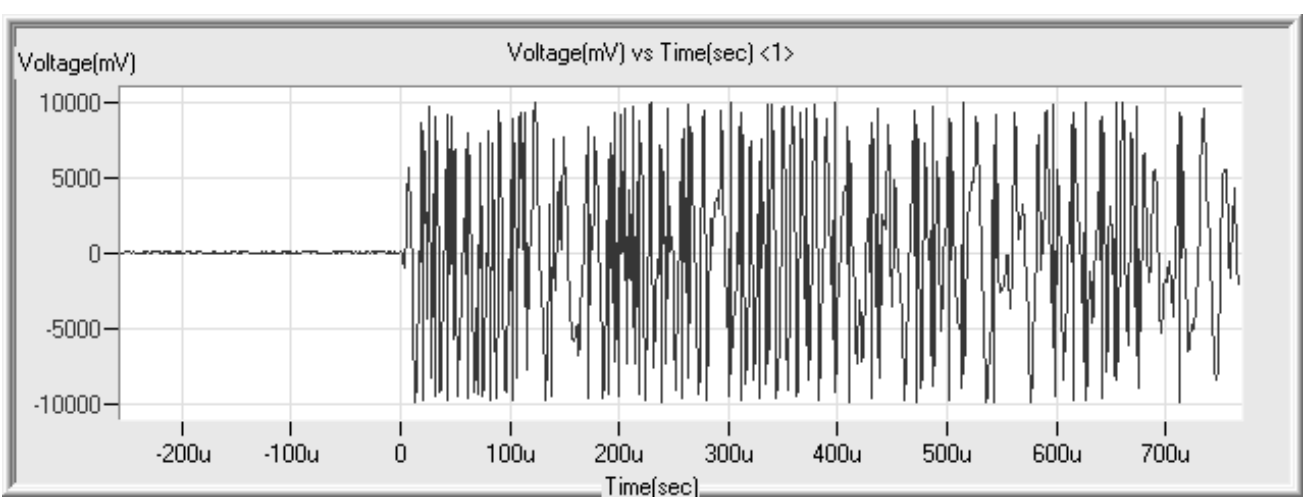

Figure 5 Continuous-type AE wave form 


\subsection{Identification of AE signals}

Due to the unpredictability and randomness of $\mathrm{AE}$ activity, it is of first importance to discern the useful AE signals from the overall signals. The AE signals are defined as the ones of which the magnitudes exceed the predefined triggering value (threshold). Due to the weakness of AE waves, two amplifiers are usually needed to intensify the signals. When the computer (data acquisition system) processes all the signals, band-pass filter is utilized to eliminate noise. Factors such as attenuation, dispersion, diffraction, and scattering could affect the AE signals propagating through the materials.

\subsection{The Kaiser Effect and Felicity Ratio of AE signals}

When materials under low cyclic loading, there are no discernible AE signals until previously applied stress levels (B) are exceeded, AE signals constantly emit from A to $\mathrm{B}$. When the material is unloaded to $\mathrm{C}$, there are no AE signals observed until the stress level B is exceeded. This phenomenon is defined as Kaiser Effect. In Figure 6, it shows the typical Kaiser Effect. As long as the loading continues, AE signals will be collected constantly. When the loading cycles come to the higher stress level D, the material is brought into unstable phase where previous microcracks develop into notable defects. AE signals are observed even before loading reaches stress level $\mathrm{D}$, which means the Kaiser effect tends to wane at high stress level. This phenomenon is defined as Felicity effect. Additionally, the Kaiser Effect could be interpreted with the Felicity ratio not less than 1.0. The Kaiser effect has been well established in homogeneous materials such metals and alloys however the mechanism of Kaiser Effect in 
heterogeneous materials such as rock, concrete still needs to be investigated (Lockner 1993). Moreover, the Kaiser/Felicity effect test is basically viable under laboratory environment due to the requirement of the accurate load control. The Felicity ratio is defined as,

$$
\text { Felicity Ratio }=\frac{P_{A E}}{P_{1 s t}}
$$

$P_{A E}$ is initial stress when AE activity starts to be observed; $P_{1 s t}$ is the maximum stress.

The deterioration process of a material usually falls into three stages, which are occurrence of defects, the stable development phase, and unstable damage. In stable conditions, the Felicity ratio of the testing material should not be lower than one; otherwise, significant damage may occur.

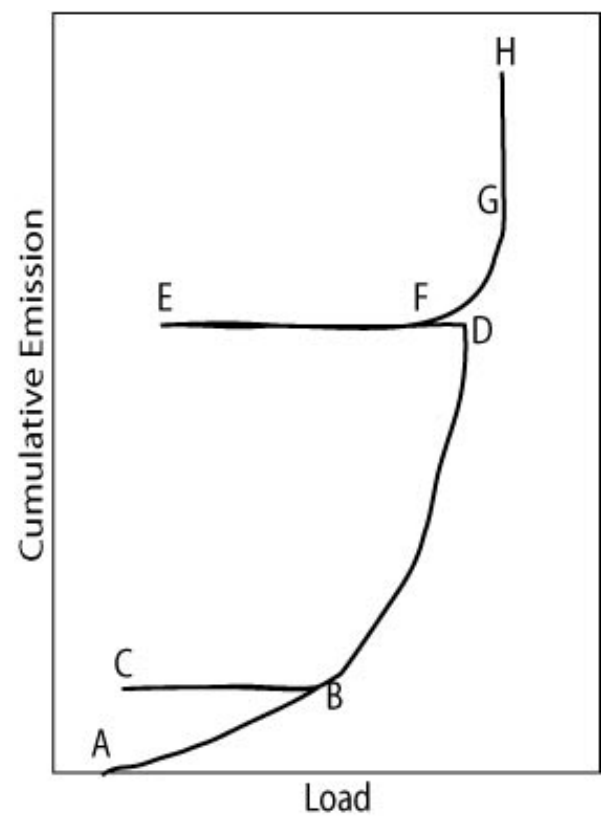

Figure 6 Kaiser/Felicity Effect in concrete (Grosse and Ohtsu 2008) 


\subsection{Factors Influencing AE Detection}

Due to variable testing scenarios, $\mathrm{AE}$ waveforms acquired could be under the influence of properties of testing materials, loading conditions, background noise, and signal traveling path. In the following, the effects of attenuation and background noise in AE detection will be explained.

\subsubsection{Attenuation}

Attenuation is defined as the loss of signal amplitude when AE signals transmit through the material. It is a common phenomenon which has been witnessed in the $\mathrm{AE}$ technique test. The amplitude of AE signals will decline rapidly in the material with high attenuation. Also, the degree of attenuation, which is correlated with frequency level, can be defined as follows,

$$
Q=2 \pi E / \Delta E
$$

where $E$ is the energy level of $\mathrm{AE}$ waves, $\Delta E$ is attenuation value over a onewavelength propagation distance (Ohtsu 1995). As discussed above, the $Q$ value of metal alloys are higher than the value in concrete.

The attenuation of AE signal amplitude can be evaluated as

$$
U(f)=\exp (-\pi f D / v Q)
$$

where $v$ is the $\mathrm{AE}$ wave velocity; $D$ is the propagating distance, and $f$ is the frequency.

\subsubsection{Background Noise}

As aforementioned in the previous section, impact loading, friction, liquid flow and even electromagnetic noise could be attributed to the sources of AE signals. In this 
research, we met the major noise issue in the freeze-thaw damage test. The operation of the thermostat in the freezer will induce both of the electromagnetic noise and acoustic noise. Thus, these undesired $\mathrm{AE}$ signals consist of background noise when performing typical cracking detection test. The noise will influence the accuracy and reliability of the testing results. So, no matter in laboratory testing or practical applications, noise control has always been an issue that needs to be properly handled.

Fortunately, researchers developed feasible techniques to filter or discern the noise in very noisy test environments (Pollock 1989). The first step is to set a proper frequency range. Noise is usually in low range. The range from $100 \mathrm{kHz}$ to 300 $\mathrm{kHz}$ is practical in $90 \%$ of the applications. However, the frequency range has inverse relationship with detecting radius. So the decision should be made discreetly between testing radius and noise control. Apart from the frequency range setting, stop the source of noise is the radical method to eliminate noise; also, damping materials can be placed at potential AE signal emitting points; moreover, special AE sensor and preamplifier are an applicable way to remove electrical noise; Other approach will include using a band-pass filter to eliminate the audible noise whose frequency is lower than the testing system configuration. Besides, other advanced techniques, which are front-end filtering and floating threshold, are employed. Furthermore, software or hardware included in the AE system is always a way to settle the noise problem.

\subsection{The AE signal feature descriptions}

In the $\mathrm{AE}$ testing, count, amplitude, duration, rise time, and energy are the five most frequently used parameters (Pollock 1989). Other parameters like threshold, RA 
value, frequency, to name a few are also widely employed in crack classification. They are defined as,

Count: As shown in

Figure 8, the number of times that an AE signal exceeds a threshold within duration. The terms "count" is also named ring-down count or threshold crossing count.

Amplitude: The maximum value of AE signal, which is in the unit of voltage when processed in the data acquisition device. It can be converted into decibel as follows,

$$
d B=20 \cdot \log _{10}\left(V_{\max } / 1 \mu V\right)-\text { preamplifier gain }
$$

Duration: It designates the time span from the starting point of the AE signal to the time of termination. The unit is usually in microsecond.

Rise time: It is referred to the time interval starting from the time of AE signal generation and the time of signal reaching its amplitude.

Energy: Area under the rectified signal envelope. It describes the magnitude of the source event over the duration of the AE hit.

Threshold: the triggering value of AE system to record waves as AE signals. The set of threshold has influence on the measuring of other AE parameters such as count, amplitude, duration and so on.

Hit: when magnitude of a signal is beyond the threshold, it will cause the data acquisition device to accumulate data.

RA value: The ratio of rise time and amplitude, which is used to identify the classification of fractures (Berkovits and Fang 1995; Grosse, Reinhardt et al. 1997). As 
shown in Figure 1, the decreasing RA value suggests the tendency of tensile fracture(Soulioti, Barkoula et al. 2009).

(a)
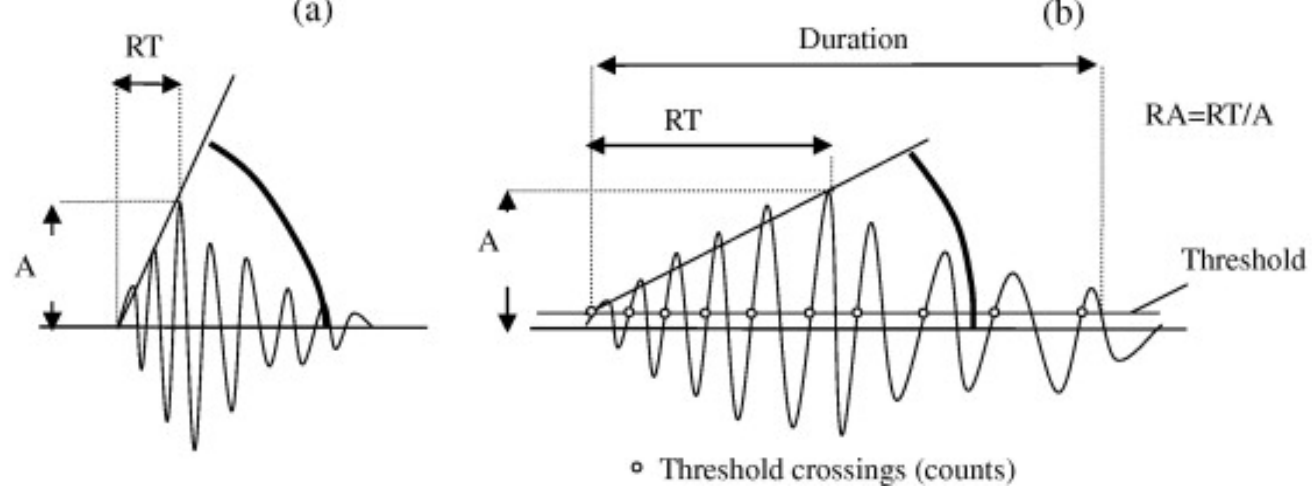

Figure 7 Typical waveforms of (a) tensile damage and (b) shear damage event. A is amplitude and RT is the rise time (Soulioti, Barkoula et al. 2009).

Average Frequency (AF): Average frequency is defined as the ratio of AE counts to duration which is expressed as equation (5). This parameter is mainly used when AE signals are difficult to obtain. The transition of average frequency value from high to low signifies the transition of failure mode from tensile to shear (Labuz, Dai et al. 1996; Soulioti, Barkoula et al. 2009).

$$
\text { Average Frequency }=\frac{\text { AE counts }}{\text { Duration }}
$$

Count to peak: the number of counts between triggering point and peak amplitude.

Initial frequency: the feature derived from "count to peak" divided by "rise time."

RMS: Root-mean-square. It is recommended to use in continuous AE signals detection. 
Frequency centroid: the ratio of a sum of frequency magnitude and a sum of sum of magnitude.

Peak frequency: the peak value in the power spectrum, which has the unit kHz.

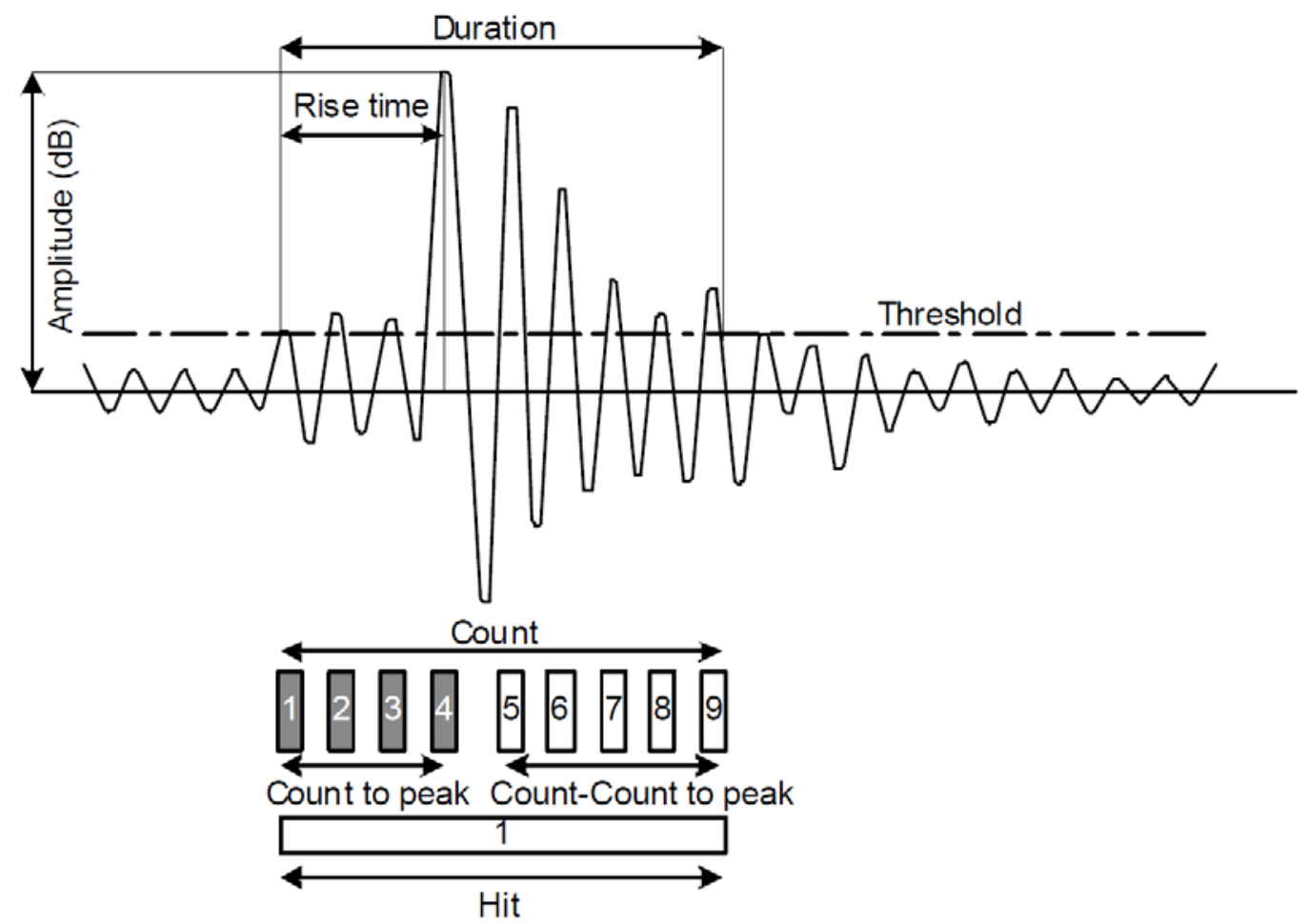

Figure 8 The typical AE signal features (Grosse and Ohtsu 2008) 


\section{Acoustic Emission Testing Methods}

\subsection{Parameter-based technique and signal-based technique}

There are two accessible approaches to precede acoustic emission research: the parameter-based technique and the signal-based technique. The parameter-based (classical) technique is known as the technique only extracting parameters from received signals without saving the waveforms. Key parameters such as hit, amplitude, count, rise time, duration are recorded to assess $\mathrm{AE}$ activities. The signal-based $\mathrm{AE}$ technique, which is also named the quantitative technique, is characterized by transforming analogue signals to electrical signals. The rapid development of computer technique enables more large storage space and faster processing rate. However, parameter-based technique is still used owing to the comparatively low financial expense and low system physical memory usage when implement long term detection.

\subsection{Advantages of parameter-based and signal-based AE techniques}

The AE technique is dynamic monitoring and is suitable to investigate the development of flaws or cracks inside of the materials. Usually the frequency range of an $\mathrm{AE}$ sensor is between $20 \mathrm{kHz}$ and $1 \mathrm{MHz}$. Parameter-based $\mathrm{AE}$ technique is advantageous when considering data acquisition and storing speed. Unlike the signalbased $\mathrm{AE}$ technique, the parameter-based $\mathrm{AE}$ system won't experience crash when processing large amount of AE signals. On the contrary, the limit parameters extracted from $\mathrm{AE}$ waves may not be feasible to interpret the $\mathrm{AE}$ signals under complex circumstances. The major advantage of signal-based $\mathrm{AE}$ technique is that the saved signal waveforms render post-processing of AE data possible. Researchers can eliminate 
noise or undesired signals through observe the waveforms. The attributes of signal-based AE technique requires large storing capacity, particularly for the long-term testing. Other assisting tools may be also needed to curtail the influence of unrelated AE data. The preference of which approach to select is primarily determined by accessibility of financial support and storing space of the computer-based AE system. 


\section{The setup of $\mathrm{AE}$ system}

As shown in Figure 9, the typical setup for an AE system consists of one to several AE sensors, a preamplifier, a main amplifier, and computer-based data acquisition devices. Additional, other accessories are necessary such as couplant and connecting cables.

\subsection{The AE sensor}

The role of the $\mathrm{AE}$ sensor is acting as a receiver to convert detected dynamic displacements or sound waves into electric signals. Today, AE sensors are already commercially available. There are two categories of sensors usually applied in the AE testing: resonant and broadband sensors. The sensitivity of a sensor can be interpreted in voltage output per vertical second. Resonance type sensors, which are usually applied in the material with high attenuation like concrete, gain higher sensitivity but lower frequency range than the broadband sensors. The typical AE resonance sensors primarily utilized today are based on piezoelectric effect of lead zirconate titanate (PZT). This piezoelectric based sensor is known to be the most ideal sensor balancing the low financial cost, high performance, and friendly operating. Generally speaking, every sensor needs to be calibrated before the testing. "The face-to-face method", which is conducted by attaching the wear plates of the two same type sensors together to render one is transmitter and the other one is receiver; "The defined sharp pulse method", which is conducted by breaking material like glass capillary on a homogenous material like steel(Pollock 1989). If the sensors cannot be mounted on the surface of the target 
objects, waveguides will be needed; however, that will make the result analysis more complicated. Other types of sensors includes laser sensor (used in testing condition with fire); optical fiber sensor (long term monitoring, corrosive conditions)

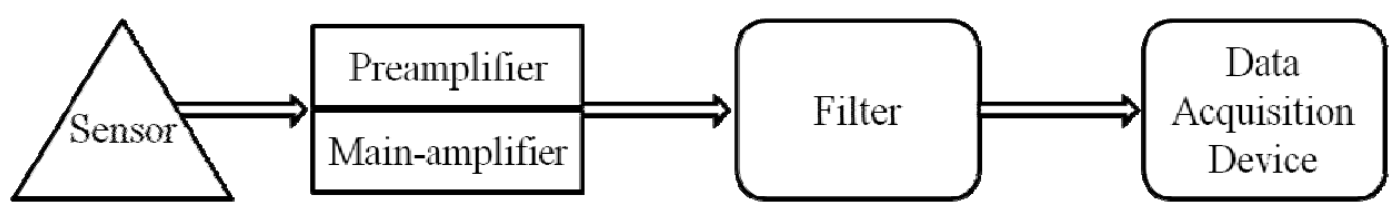

Figure 9 Typical AE system setup (by author)

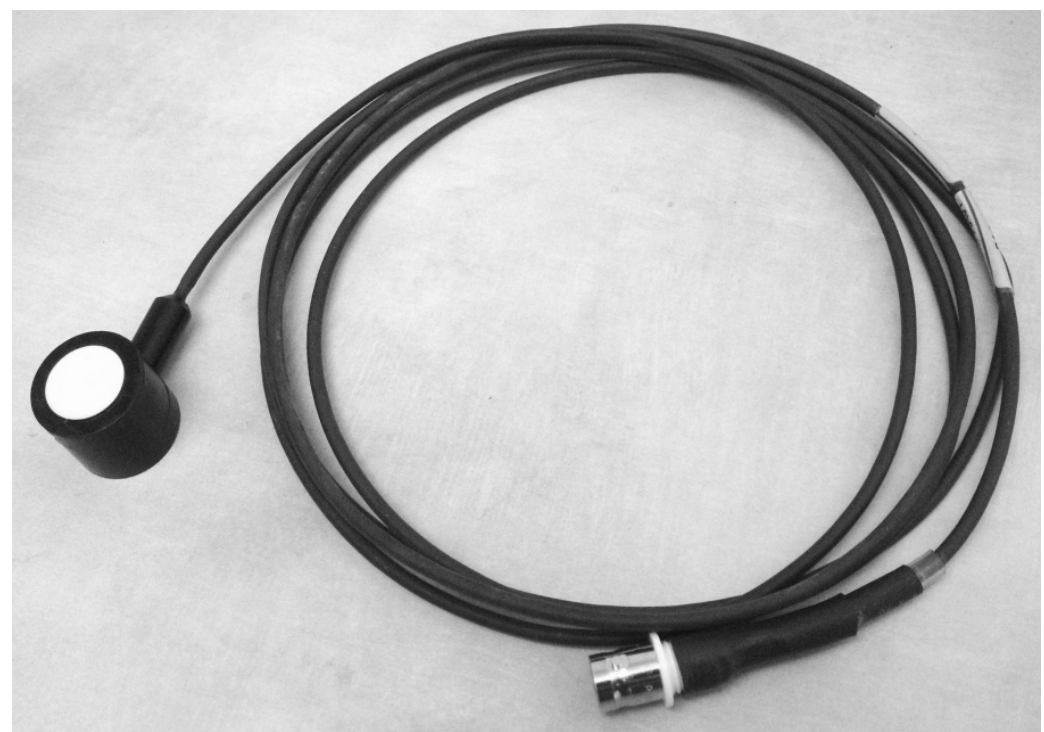

Figure 10 ISR6 sensor (by author) 


\subsection{Amplifier}

AE signals are generally magnified by pre-amplifier and main-amplifier, and then processed by data acquisition system to exclude noise. Typically, AE signals are filtered by band-pass filter. The gain of amplifier (dB) is expressed,

$$
d B=20 \cdot \log _{10}\left(V_{0} / V_{i}\right)
$$

where $V_{0}$ is input voltage, $V_{i}$ is output voltage. As a reference, the signals from concrete are usually magnified $60 \mathrm{~dB}$ to $100 \mathrm{~dB}$. The filter ranging from $1 \mathrm{kHz}$ to $2 \mathrm{MHz}$ is recommended.

In this research, a 2/4/6 preamplifier was purchased from MISTRAS Group. It is designed three preamplifier gain ranges that are $20 \mathrm{~dB}, 40 \mathrm{~dB}$, and $60 \mathrm{~dB}$. It allows the user to switch as required and provides low pass, wide pass, and band pass filter choices. Main amplifier was integral in the PCI-2 card.

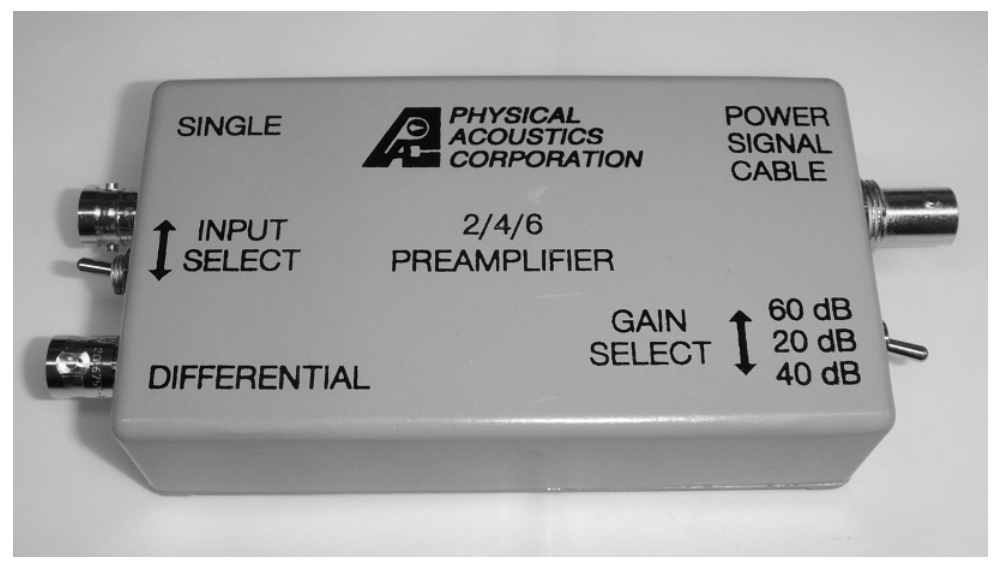

Figure 11 2/4/6 preamplifier (by author) 


\subsection{Couplant and cable}

The choice of couplant is crucial to the accuracy of the test because the amplitude of AE signals is low. The properties of ideal couplant should feature low impedance comparing to the materials under tested and high fidelity when signals transmit. Wax and grease are of this kind to be selected. In the testing, high vacuum grease is employed as recommended in some papers. When placing a sensor, the contacting surface between sensor and material should be smooth. Surface grinding is needed if necessary. The couplant layer should be even and it is essential to get rid of bubbles and make couplant layer as thin as possible to guarantee good acoustic transmission. The connecting cables should be chosen to eliminate electro-magnetic interference.

\subsection{Data acquisition device}

A data acquisition system (showed in Figure 12) named PCI-2 (PCI is "Peripheral component interconnect") card is capable of analyzing AE parameters including count, hit, event, rise time, duration, amplitude, energy, RMS voltage, frequency spectrum, arrive-time and so forth. This device employed in this research is purchased from MISTRAS Group. PCI-2 card can be housed into most standard PC. Each PCI-2 card includes two data acquisition channels that support high speed data transferring and processing. There are 4 integral low pass filters and 6 high pass filters. PCI-2 AE system is characterized as low noise and low threshold performance by using 18 bit analogdigital conversion, 40 Msample/second acquisitions with sample average and automatic offset control. Therefore, PCI-2 card has been applied in the field like university laboratory tests, where low cost, low channels and low noise are required. 
The AEwin software is a 32 bit windows-based operating program for AE data displaying and post-processing. PCI-2 AE system records AE waveforms and enables researchers replaying and plotting multiple graphs at the same time by using AEwin Software. When implementing real-time detecting, the technicians are able to monitor the occurrence of the AE signals by observing the change of the displayed waveforms captured by the sensors; if the test is long-term and technicians are not available all the time, the waveforms can be saved in the computer's hardware for later use. These AE signal information can be replayed and picked out as required. Moreover, the signal curves can be output as picture file; also acquired AE signal information can be exported as .txt file. That renders the technicians possible to plot desired curves in Office Excel or Matlab to conduct more data analysis.

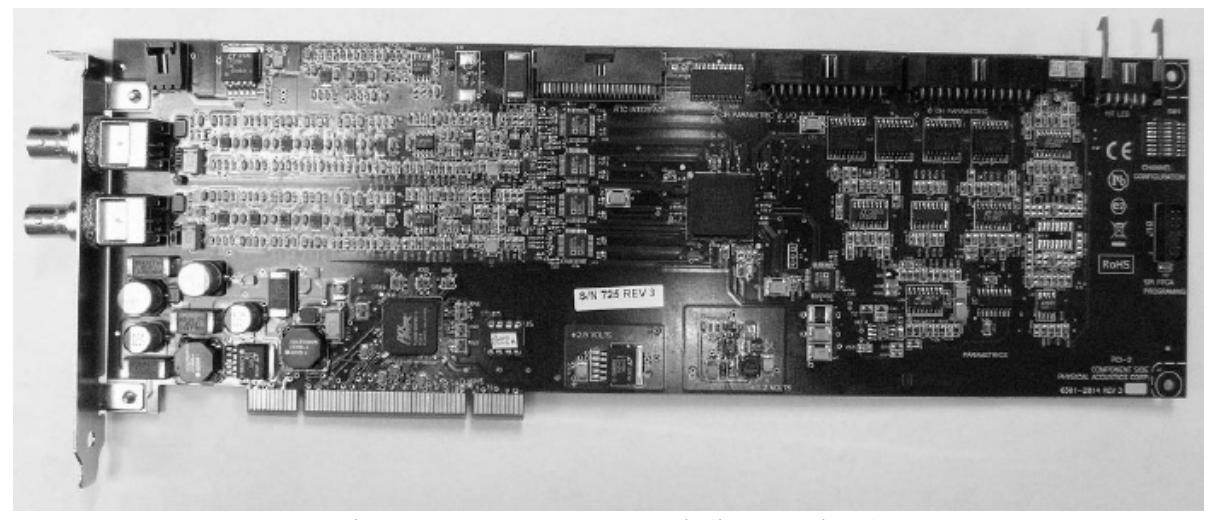

Figure 12 PCI-2 card (by author) 


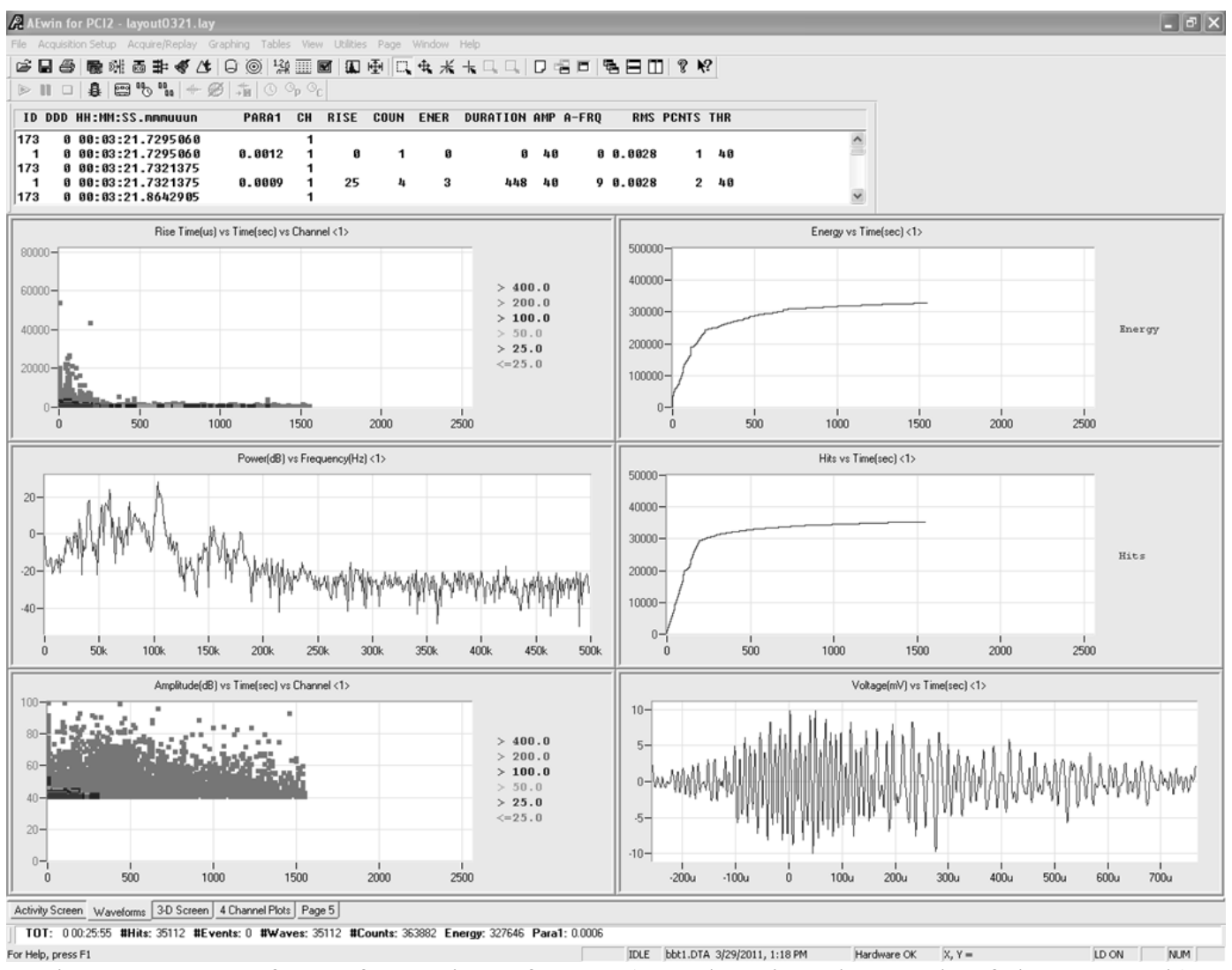

Figure 13 Interface of AEwin software (not showing the work of the research) 


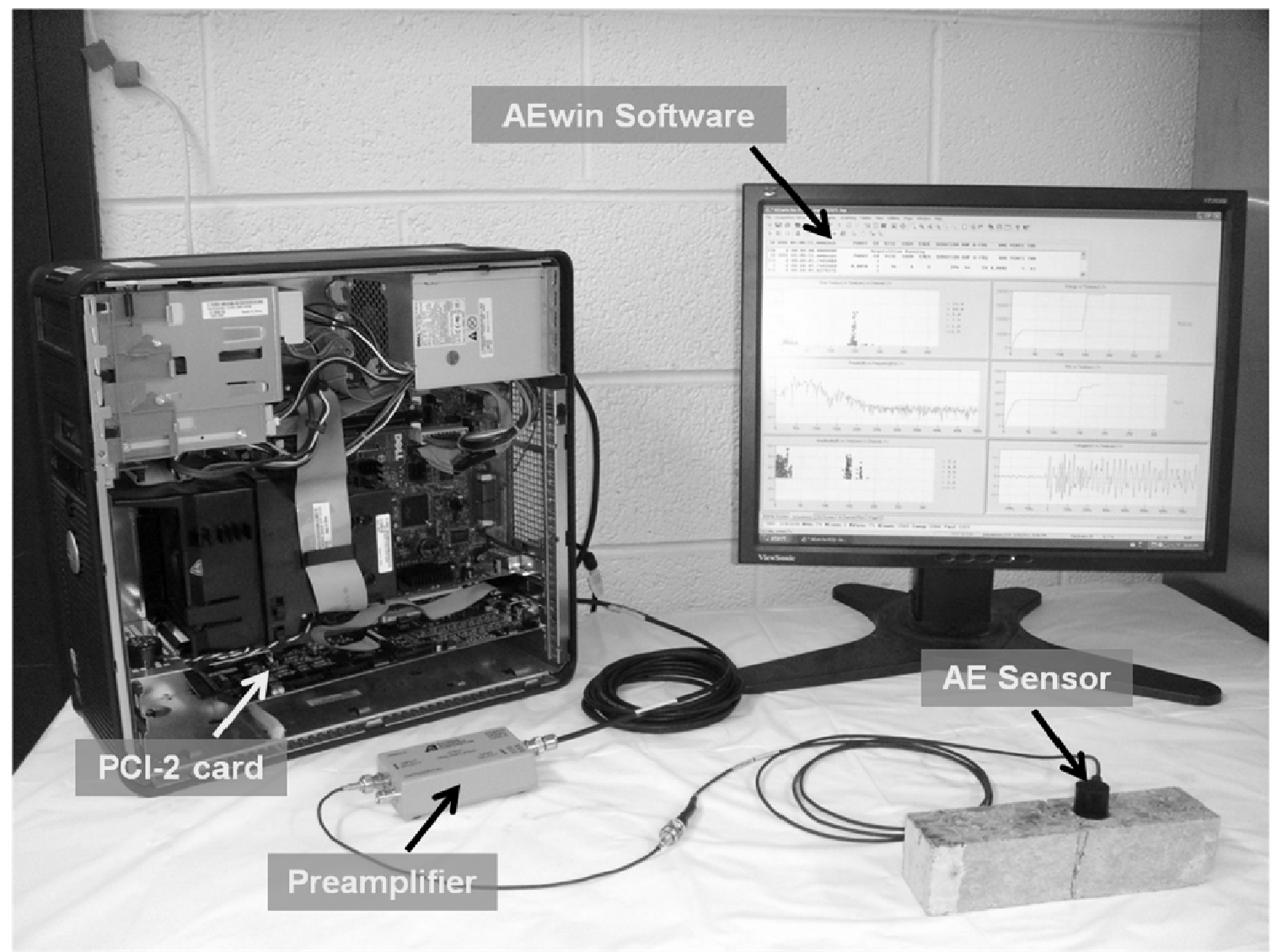

Figure 14 The AE system instrumentation setup in research (by author) 


\section{Research work}

\subsection{AE damage detection with pencil lead test}

\subsubsection{The pencil lead test setup and procedure}

The pencil lead test is usually conducted to test the performance of the AE system by analyzing the AE signal waves. The pencil lead fracture test was conducted under laboratory environment. The purpose of this test was to determine the attenuation of $\mathrm{AE}$ signals when transmitting through concrete materials. Also, as a preliminary test, pencil lead test was a good attempt on how to set up the parameters for the following test and check the workability of the AE system.

The threshold of the AE system was set to $40 \mathrm{~dB}$ and its operating frequency range was from $20 \mathrm{kHz}$ to $200 \mathrm{kHz}$. In this test, an ordinary mechanical pencil was used and the asphalt concrete beam served as the medium where AE waves traveling (shown in Figure 15). Ten testing spots with the interval of 2 in (about $0.05 \mathrm{~m}$ ) were select along the longitudinal direction of the beam to break the pencil lead. As indicated in Figure 16, signal attenuation effect was observed with sensor detection at difference fracture locations. As shown in Figure 17, similar AE waveforms were acquired at each time when the pencil lead fracture occurred; however, the amplitude of the AE signals decrease with the distance between the fracture location and the sensor. Meanwhile, additional AE signals were recorded especially at the location close to the $\mathrm{AE}$ sensor. Generally speaking, the fracture of pencil lead emits burst type AE signal. The waveforms at fracture location 1 and 8 are shown in Figure 18. It again shows the signal waveform amplitudes decreasing with distances from pencil-lead fracture location and 
the sensor. However, several signals were detected during early testing times. These other signals collected during early testing times could be considered as noise or irrelevant signals. The potential reasons could be: the pencil tip impacted the asphalt concrete beam after the fracture of lead; the friction caused by the slip of pencil lead. Table 2 listed the features of the captured AE signals from 8 fracture locations in the pencil lead test. This test also indicated the AE system can successfully detect acoustic emission signals travel through asphalt concrete specimens.

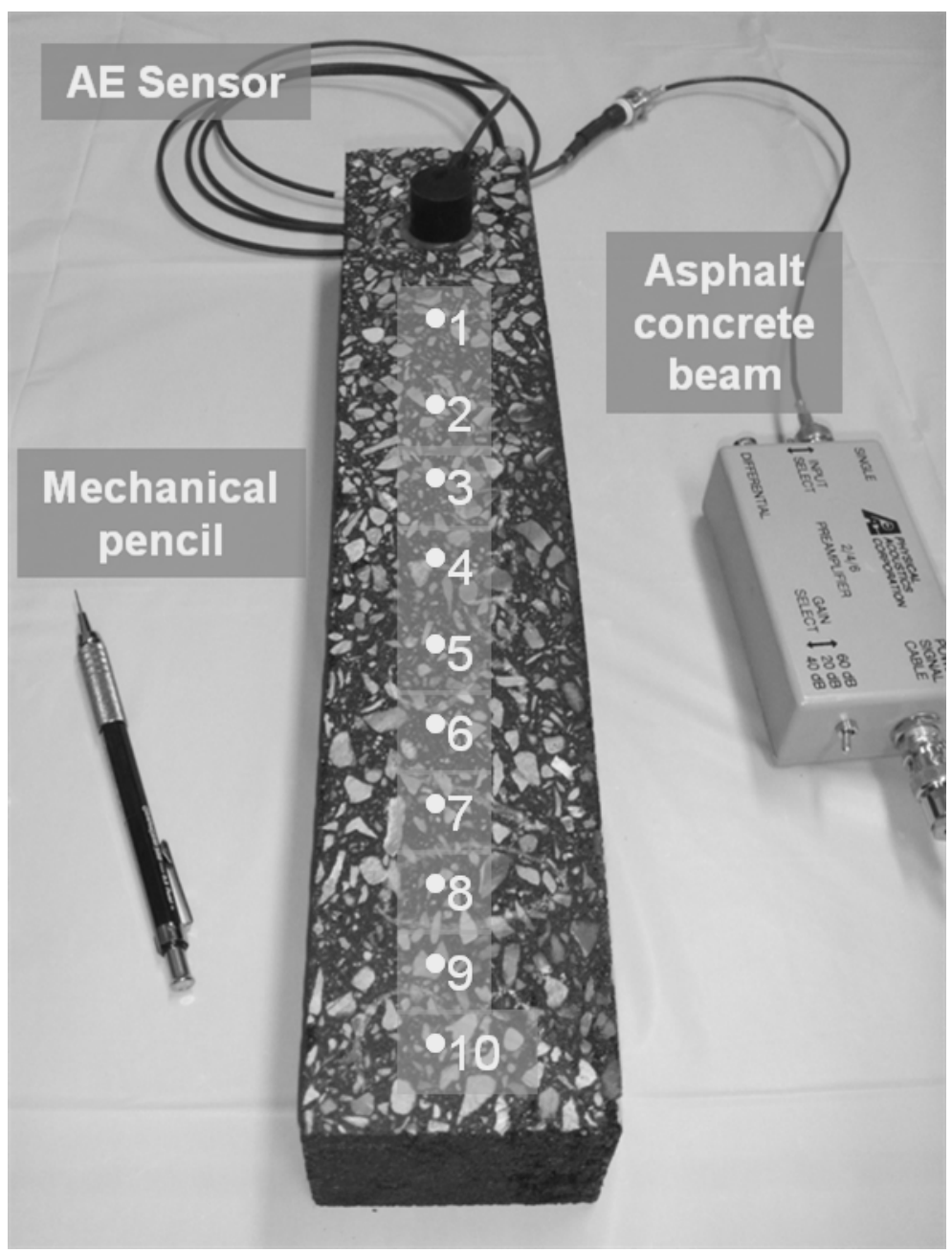

Figure 15 Pencil lead test setup (by author) 


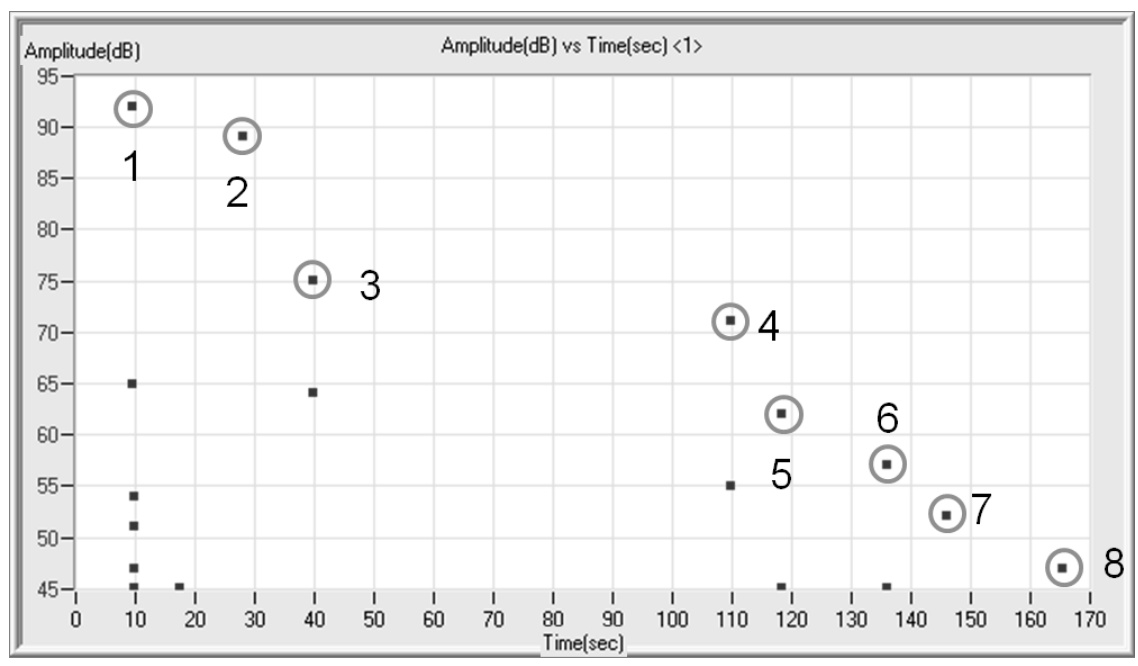

Figure 16 Received AE signals in pencil lead test

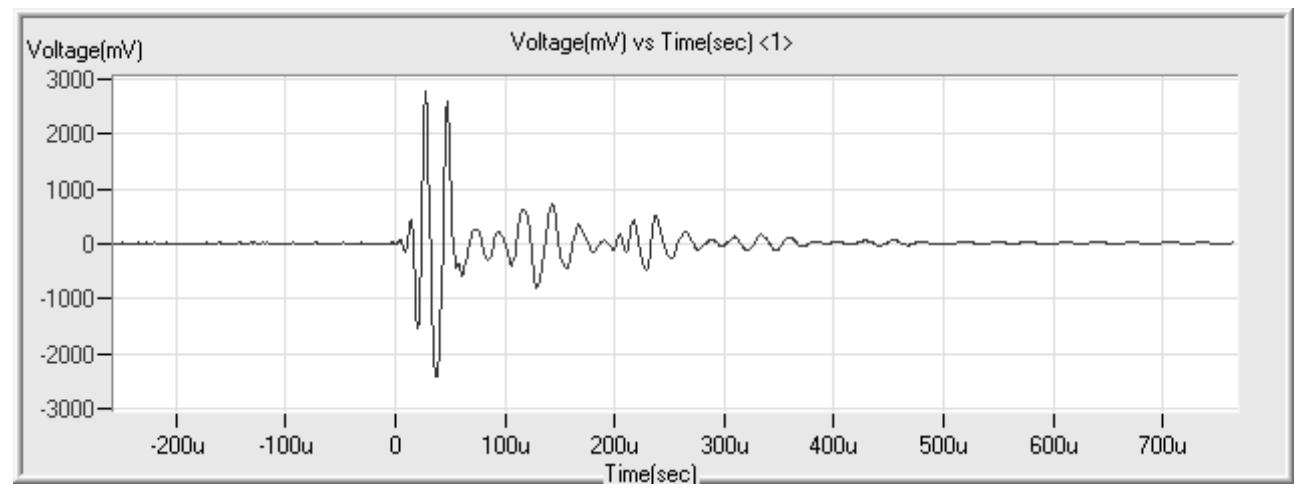

(a)

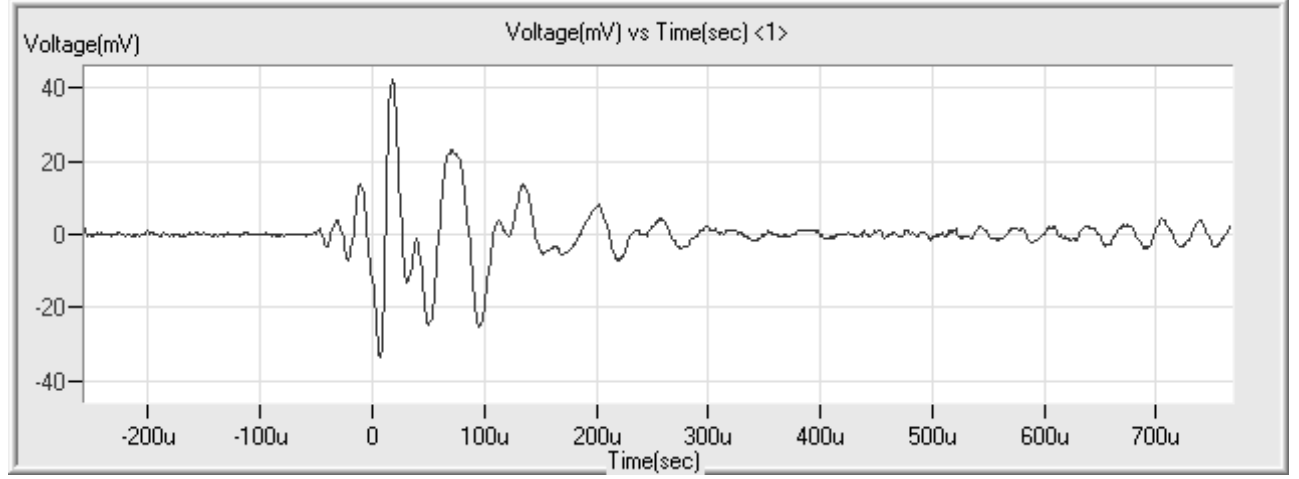

(b)

Figure 17 The signal waveform collected from pencil lead fracture test at 1 st location (a) and at 8th location (b); the waveform amplitudes decreasing with distances from pencillead fracture location and the sensor. 
Table 2 Summary of the features of AE signals from pencil lead test

\begin{tabular}{ccccccccc}
\hline Hit & $\begin{array}{c}\text { Time } \\
(\mathbf{M M : S S . m )}\end{array}$ & $\begin{array}{c}\text { Rise time } \\
(\boldsymbol{\mu})\end{array}$ & Count & Energy & $\begin{array}{c}\text { Duration } \\
(\boldsymbol{\mu s})\end{array}$ & $\begin{array}{c}\text { Amplitude } \\
(\mathbf{d B})\end{array}$ & $\begin{array}{c}\text { Average } \\
\text { frequency } \\
(\mathbf{k H z})\end{array}$ & RMS (V) \\
\hline $\mathbf{1}$ & $00: 09.7$ & 20 & 28 & 243 & 731 & 92 & 38 & 0.0194 \\
$\mathbf{2}$ & $00: 28.0$ & 24 & 23 & 194 & 563 & 89 & 41 & 0.0002 \\
$\mathbf{3}$ & $00: 39.9$ & 30 & 13 & 39 & 350 & 75 & 37 & 0.0002 \\
$\mathbf{4}$ & $01: 49.8$ & 33 & 12 & 32 & 356 & 71 & 34 & 0.0002 \\
$\mathbf{5}$ & $01: 58.4$ & 29 & 9 & 12 & 254 & 62 & 35 & 0.0002 \\
$\mathbf{6}$ & $02: 16.1$ & 20 & 7 & 6 & 164 & 57 & 43 & 0.0002 \\
$\mathbf{7}$ & $02: 26.1$ & 15 & 3 & 2 & 98 & 52 & 31 & 0.0002 \\
$\mathbf{8}$ & $02: 45.4$ & 3 & 1 & 0 & 17 & 47 & 59 & 0.0002 \\
\hline
\end{tabular}

\subsubsection{The Quantitative Evaluation of Attenuation}

This section is aimed at evaluating the attenuation of the AE wave propagating through the asphalt concrete material by equation (2) and equation (3) proposed in the previous section and comparing with the laboratory test results (shown in Table 2). From equation (3), the attenuation factor is calculated as follows,

$$
U(f)=\exp (-\pi f D / v Q)
$$

where $f$ is $38 \mathrm{kHz}$ for average frequency value from the pencil lead fracture; $D$ is $0.05 \mathrm{~m}$ for average interval of two facture locations; $v$ is $3600 \mathrm{~m} / \mathrm{s}$ (The_engineering_toolbox); $Q$ is 10 for typical use (Ohtsu 1995) as listed in Table 3.

Table 3 Parameters for evaluating attenuation

\begin{tabular}{cccc}
\hline $\begin{array}{c}\boldsymbol{f} \\
(\mathbf{k H z})\end{array}$ & $\begin{array}{c}\boldsymbol{D} \\
(\mathbf{m})\end{array}$ & $\begin{array}{c}\boldsymbol{v} \\
(\mathbf{m} / \mathbf{s})\end{array}$ & $\mathbf{Q}$ \\
\hline 38 & 0.05 & 3600 & 10 \\
\hline
\end{tabular}


As shown in Table 4, the attenuation factors at location 2-8 were calculated with the relation (3) based on the relative distance from the location 1 . The calculated AE signal amplitude at other locations is also calculated with the multiplication of the attenuation factor $U(f)$ and AE signal amplitude at location 1. The measured AE signal amplitude at location 1 is $92 \mathrm{~dB}$. The calculated amplitude values at locations 2 to 8 are compared with the detected AE signal amplitude. The contrast of calculated AE signal amplitude and laboratory detected AE signal amplitude is shown in Table 4, which shows the agreement between the laboratory test results and quantitative evaluation results.

Table 4 The contrast of AE signal amplitude between pencil lead test result and attenuation calculation

\begin{tabular}{ccccc}
\hline Hit & $\begin{array}{c}\boldsymbol{D} \\
(\mathbf{m})\end{array}$ & $\boldsymbol{U}(\boldsymbol{f})$ & $\begin{array}{c}\text { Detected } \\
\text { AE Signal } \\
\text { Amplitude } \\
(\mathbf{d B})\end{array}$ & $\begin{array}{c}\text { Calculated } \\
\text { AE Signal } \\
\text { Amplitude } \\
(\mathbf{d B})\end{array}$ \\
\hline 1 & - & - & 92 & - \\
2 & 0.05 & 0.984 & 89 & 90.5 \\
3 & 0.1 & 0.967 & 75 & 86.1 \\
4 & 0.15 & 0.951 & 71 & 71.4 \\
5 & 0.2 & 0.936 & 62 & 66.4 \\
6 & 0.25 & 0.920 & 57 & 57.1 \\
7 & 0.3 & 0.905 & 52 & 51.6 \\
8 & 0.35 & 0.890 & 47 & 46.3 \\
\hline
\end{tabular}




\subsection{Three-point single-edge notched beam bending (SEB) test with concrete specimens}

\subsubsection{The test setup}

The SEB test was conducted with the MTS mechanical loading and the AE damage detection. This test is aimed at proving the correlation between mechanical test result and acquired AE data. A concrete cement beam $(2 " \times 2$ " $\times 8$ ") with a 0.4 inch notch at the mid-span, was employed. The span between the roller supports is 6 inches. Two knife edges were arranged at each sides of the notch symmetrically. Crack tip opening displacement (CTOD) was measured with the clip gauge that detected the holding displacement between the two knife edges when testing proceeded. To correlate the $\mathrm{AE}$ activity and crack propagation, the detected $\mathrm{AE}$ waveforms were recorded with the $\mathrm{AE}$ system and the loading vs. CTOD curve was obtained with the MTS system.

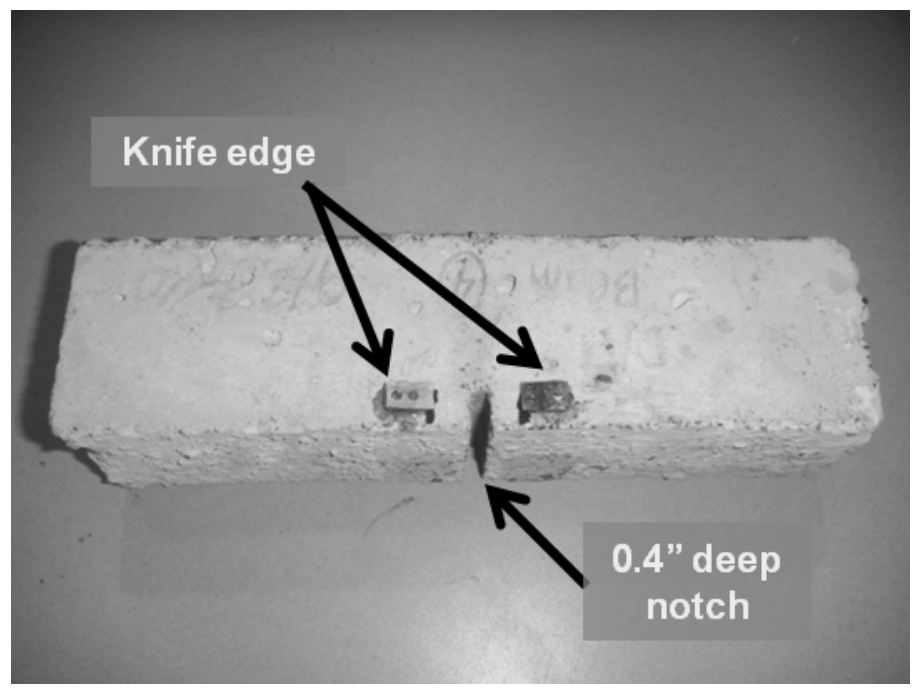

Figure 18 The concrete specimen with clip gauge for the SEB test (by author) 


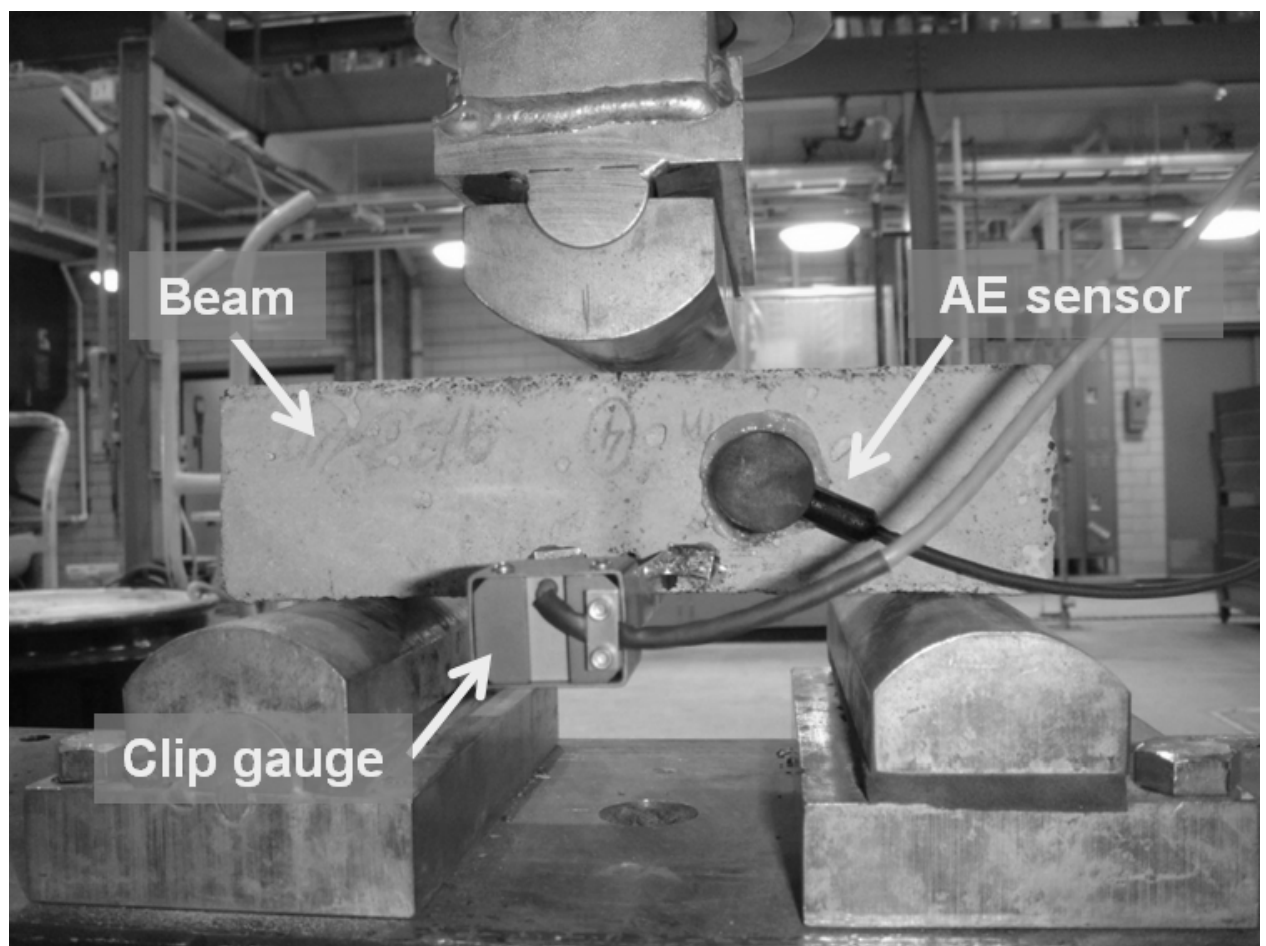

Figure 19 The instrumentation setup of SEB test with UTM system, clip gauge and AE damage detection system (by author)

\subsubsection{Test Procedure}

The AE system was also launched to acquire AE damage waveform simultaneously when the MTS started to operate. AE sensor was mounted near the notch without obstructing the potential crack developing path. When the loading continuous exerting on the beam, CTOD value kept increased together with the increment of force. It is not until the first crack occurs that the load started to reduce and at the same time the crack width of the damaged beam continued growing. On the other hand, usually, the dramatic increase of $\mathrm{AE}$ signals could be associated with the generation of defects. Generally, it is impossible to designate each AE waveform (indicated with circled dot in Figure 20) with the particular crack in concrete. The two AE events with high amplitudes indicated in the figure are related to crack initiation and quick propagation during the 
loading. The first dot with circle is the possible AE event signifying the generation of first crack. In Figure 20, it shows a dense area of AE signals concentrated around the $15^{\text {th }}$ second. As shown in Figure 21 and Figure 22, the graphs combined the data acquired from the AE system and data from MTS together to probe the correlation of them. Ideally, the peak loading of mechanical testing and the dramatic increase of AE hit histogram should take place concurrently. This result, although not perfectly fit, reflect the trend to some extent. One reason could be responsible for is that the two testing systems were launched separately. So the time gap may exist. Moreover, when the test specimen was in position, the loading cell was lowered to the place that it almost contacted the surface of the specimen. Therefore, that caused more time lap between the starting time of the two systems. From this test, it showed that AE technique can be applied with mechanical testing approach and also it demonstrated that the workability of AE on providing internal concrete damage under loading.

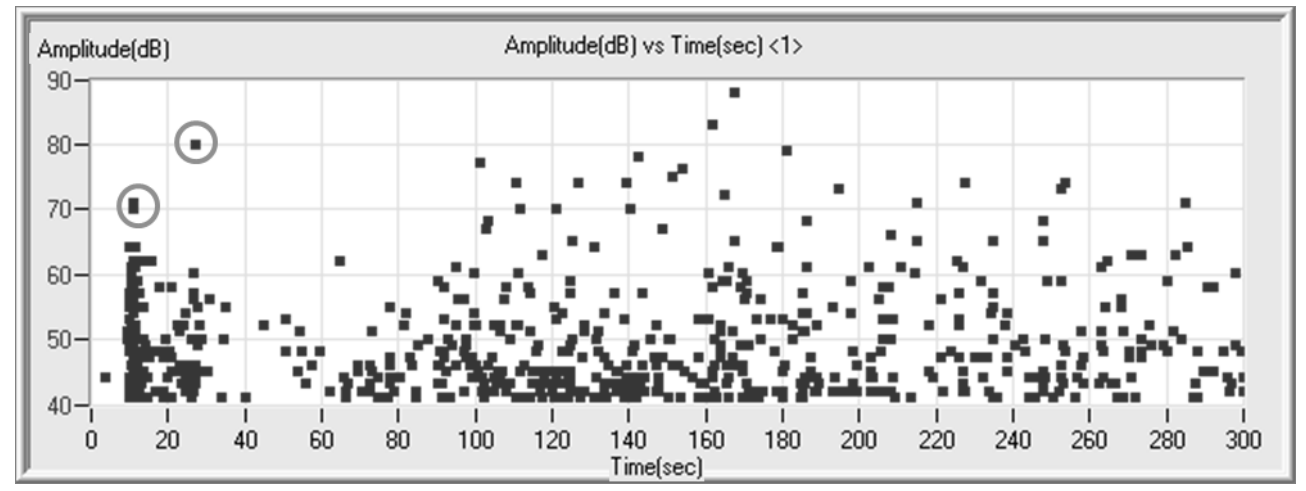

Figure 20 The scatter point graph of hit amplitudes vs. testing time for one concrete SEB test 


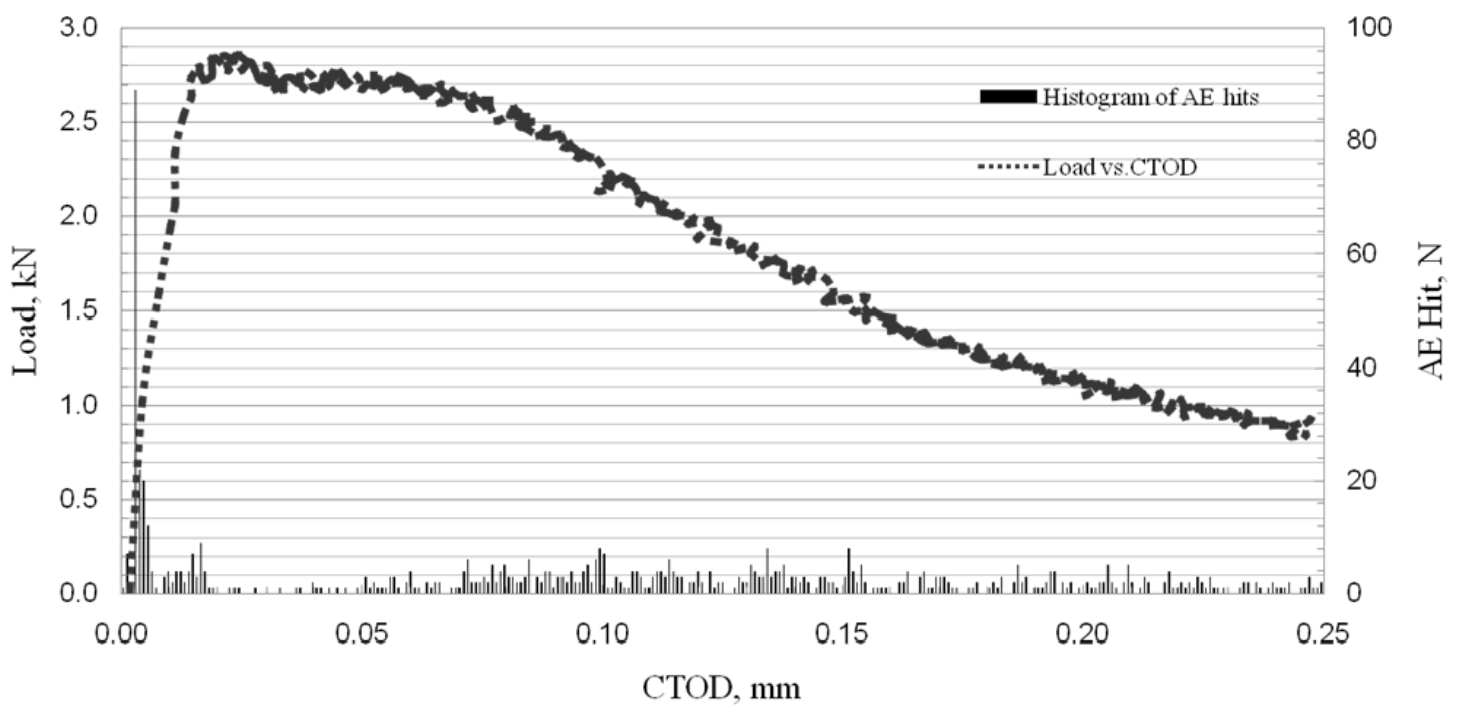

Figure 21 The histogram of hits vs. CTOD and load vs. CTOD; the first crack detected by AE system (showed as a peak jump in the histogram) is related to crack initiation and propagation during damage process (showed in dot line).

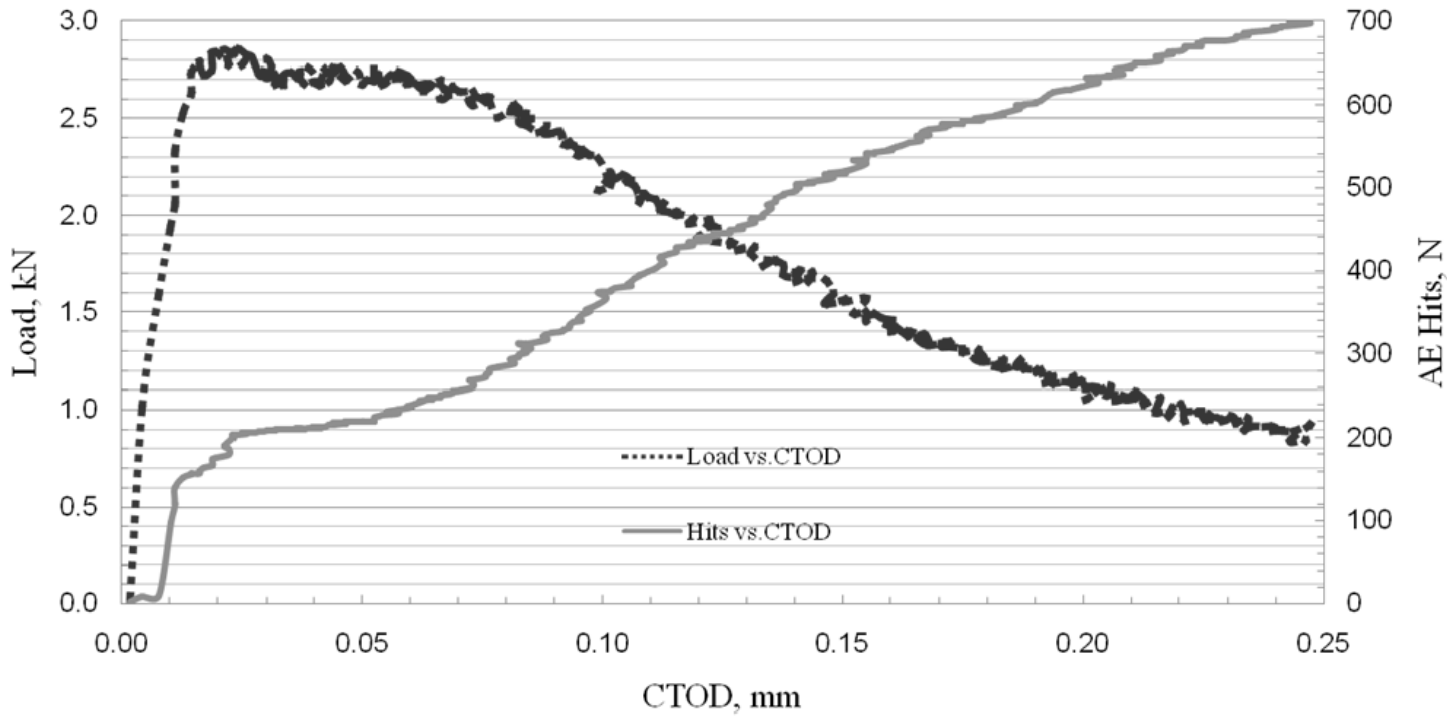

Figure 22 The correlation between cumulative AE hits curve (showed in solid line) and load-CTOD curve (showed in dot line) during the damage process 


\subsubsection{Statistical analysis and discussion}

Referring to the previous research (Chen and Liu 2004), the fracture probability of a microstructure conforms to the Weibull distribution (Weibull 1951). The typical probability density Weibull function:

$$
f(x ; \lambda, k)=\frac{k}{\lambda}\left(\frac{x}{\lambda}\right)^{k-1} e^{-(x / \lambda)^{k}} \quad x \geq 0
$$

The cumulative distribution function for the Weibull distribution is

$$
F(x ; \lambda, k)=1-e^{-(x / \lambda)^{k}} \quad x \geq 0
$$

where $x$ is random variable, shape parameter $k$ defined as the Weibull modulus, $\lambda$ is scale parameter.

In Chen and Liu's research (Chen and Liu 2004), although the situation of threepoint bending test is more complex than the uniaxial tensile loading scenario. The Weibull function with modification was still used to represent the rupture probability density function:

$$
f(\delta)=\theta m\left(\delta-\delta_{0}\right)^{m-1} \exp \left[-\theta\left(\delta-\delta_{0}\right)^{m}\right]
$$

where $\delta_{0}$ is the displacement of clip gauge when the first $\mathrm{AE}$ signal emitted.

Then, the rupture probability function is up to a deflection level $\delta$

$$
F(\delta)=\int_{0}^{\varepsilon} f(\delta)=1-\exp \left[-\theta\left(\delta-\delta_{0}\right)^{m}\right]
$$

Due to the rupture probability density can be given as the ratio of $\mathrm{AE}$ hit ratio $d N_{\delta} / d \delta$ to the total $\mathrm{AE}$ events $N_{t o t}$ acquired by the $\mathrm{AE}$ system,

$$
f(\delta)=\frac{d N_{\delta}}{d \delta} / N_{t o t}
$$


where $N_{\delta}$ is the number of cumulated AE events;

Thus, the rupture probability is,

$$
F(\delta)=N_{\delta} / N_{t o t}
$$

From the equations (9)-(12), the relationships are built

$$
\begin{gathered}
f(\delta)=\left(d N_{\delta} / d \delta\right) / N_{t o t}=\theta m\left(\delta-\delta_{0}\right)^{m-1} \exp \left[-\theta\left(\delta-\delta_{0}\right)^{m}\right] \\
F(\delta)=N_{\delta} / N_{t o t}=1-\exp \left[-\theta\left(\delta-\delta_{0}\right)^{m}\right]
\end{gathered}
$$

As shown in Figure 23, simple linear regression analysis to the acquired data was conducted to determine the $m$ and $\theta$ values. The standard expression of the linear regression is

$$
y=a x+b
$$

From equation (14), it yields

$$
\ln \left[-\ln \left(1-N_{\delta} / N_{t o t}\right)\right]=m \ln \left(\delta-\delta_{0}\right)+\ln \theta
$$

where $\left.y=\ln \left[-\ln \left(1-N_{\delta} / N_{t o t}\right)\right] ; x=\ln \left(\delta-\delta_{0}\right)\right] ; a=m ; b=\ln \theta$.

According to the linear regression analysis, the values of $m$ and $\theta$ were determined. As shown in

As shown in Figure 24, the Weibull function is able to describe the trend of AE event accumulation in three-point beam bending test when of low AE quantity level. In Figure 25, the histogram of the rupture probability density function with calibrated Weibull distribution vs. CTOD is shown.

Table $5 m, \theta, \delta_{0}$, and $R^{2}$

\begin{tabular}{cccc}
\hline $\boldsymbol{m}$ & $\boldsymbol{\theta}$ & $\boldsymbol{\delta}_{\mathbf{0}}$ & $\boldsymbol{R}^{2}$ \\
\hline 0.9280 & 8.1011 & 0.00172 & 0.6170 \\
\hline
\end{tabular}




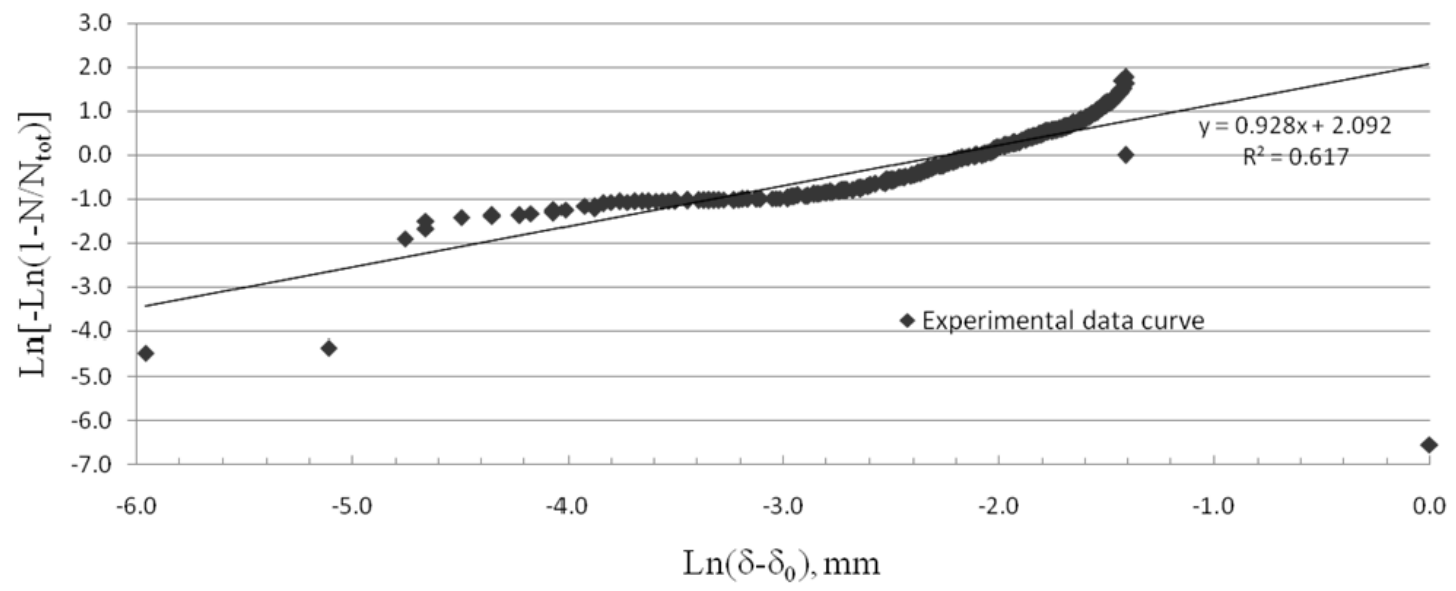

Figure 23 Linear regression fitting curve to determine $m$ and $\theta$ in the Weibull distribution

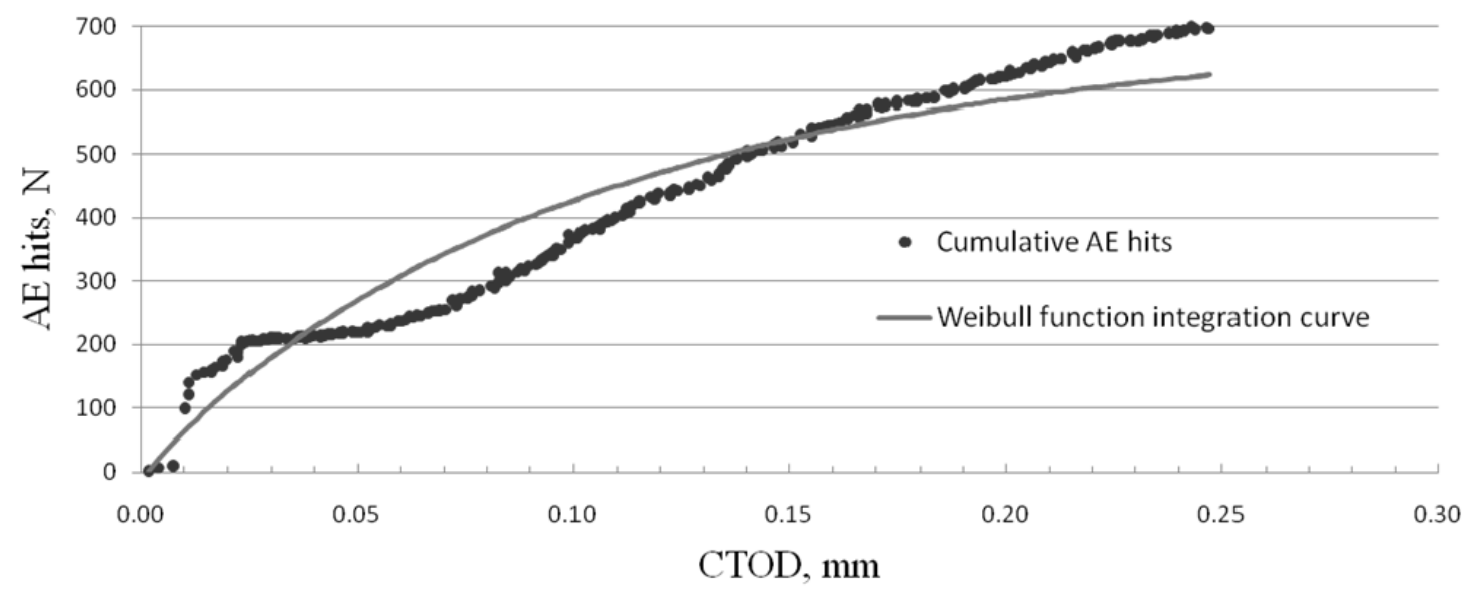

Figure 24 The Weibull function integration curve (the rupture probability function multipling the total hit number) and the cumulative AE hit curve vs. CTOD 


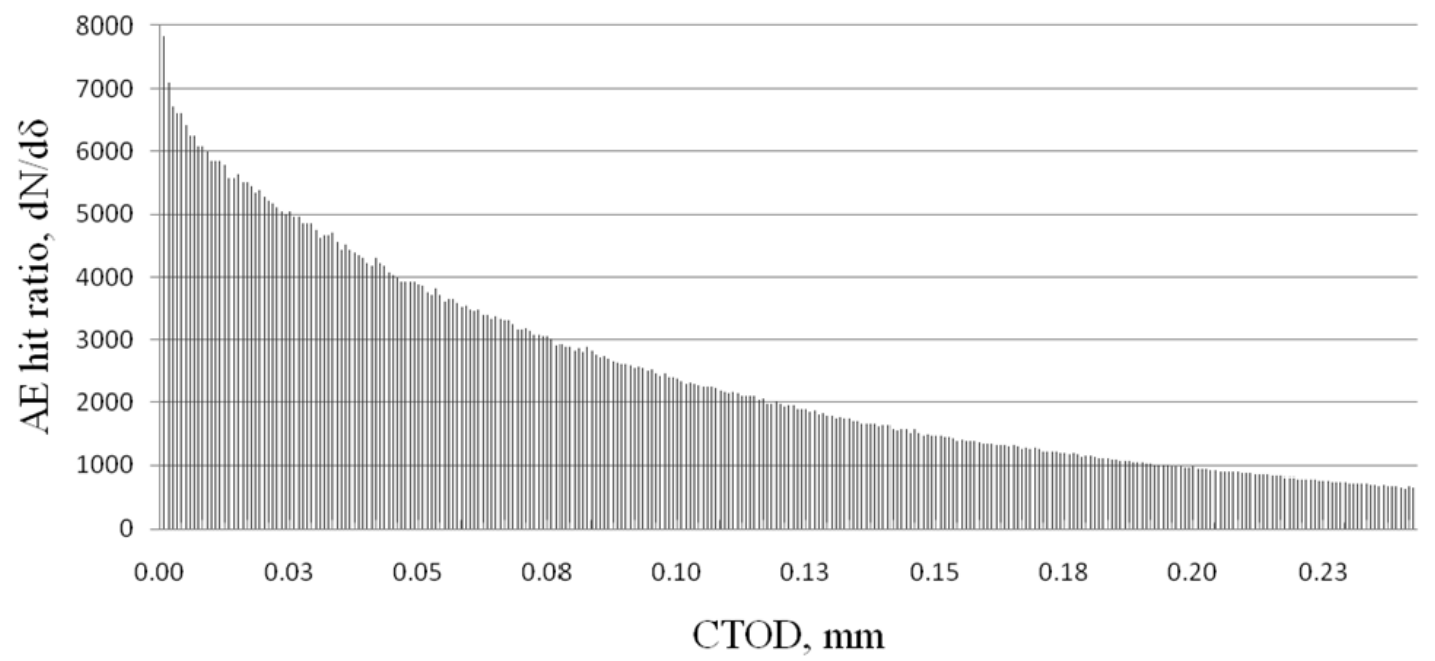

Figure 25 The histogram of the rapture probability density function with the calibrated Weibull distribution vs. CTOD

The detected AE signal data is compared with calculated AE signal data. The mean value of detected $\mathrm{AE}$ hits is 431 and deviation is 181.9; mean value of the calculated $\mathrm{AE}$ hits is 434.4 and the deviation is 159.8 . The In Table 7, relative error is calculated,

$$
R E_{i}=\frac{y_{2, i}-y_{1, i}}{y_{1, i}}
$$

where $y_{1, i}$ is cumulative $\mathrm{AE}$ hits from experimental test; $y_{2, i}$ is the calculated AE hits from the calibrated Weibull distribution function.

Standard deviation is calculated from

$$
\sigma=\sqrt{\frac{1}{N} \sum_{i=1}^{N}\left(R E_{i}-\mu\right)^{2}}
$$

where $N$ is the number of samples; $\mu$ is average value of relative error. The result is shown in Table 7, which shows the agreement between experimental data and calculated data. 
, the $m$ and $\theta$ values are related to the brittleness and geometry properties of the concrete specimens. The coefficient of determination, $R^{2}$, shows how close the two curves are correlated. The value of $R^{2}$ is between 0 (not related) to 1 (perfect related).

As shown in Figure 24, the Weibull function is able to describe the trend of AE event accumulation in three-point beam bending test when of low AE quantity level. In Figure 25 , the histogram of the rupture probability density function with calibrated Weibull distribution vs. CTOD is shown.

Table $5 m, \theta, \delta_{0}$, and $R^{2}$

\begin{tabular}{cccc}
\hline $\boldsymbol{m}$ & $\boldsymbol{\theta}$ & $\boldsymbol{\delta}_{\mathbf{0}}$ & $\boldsymbol{R}^{\mathbf{2}}$ \\
\hline 0.9280 & 8.1011 & 0.00172 & 0.6170 \\
\hline
\end{tabular}

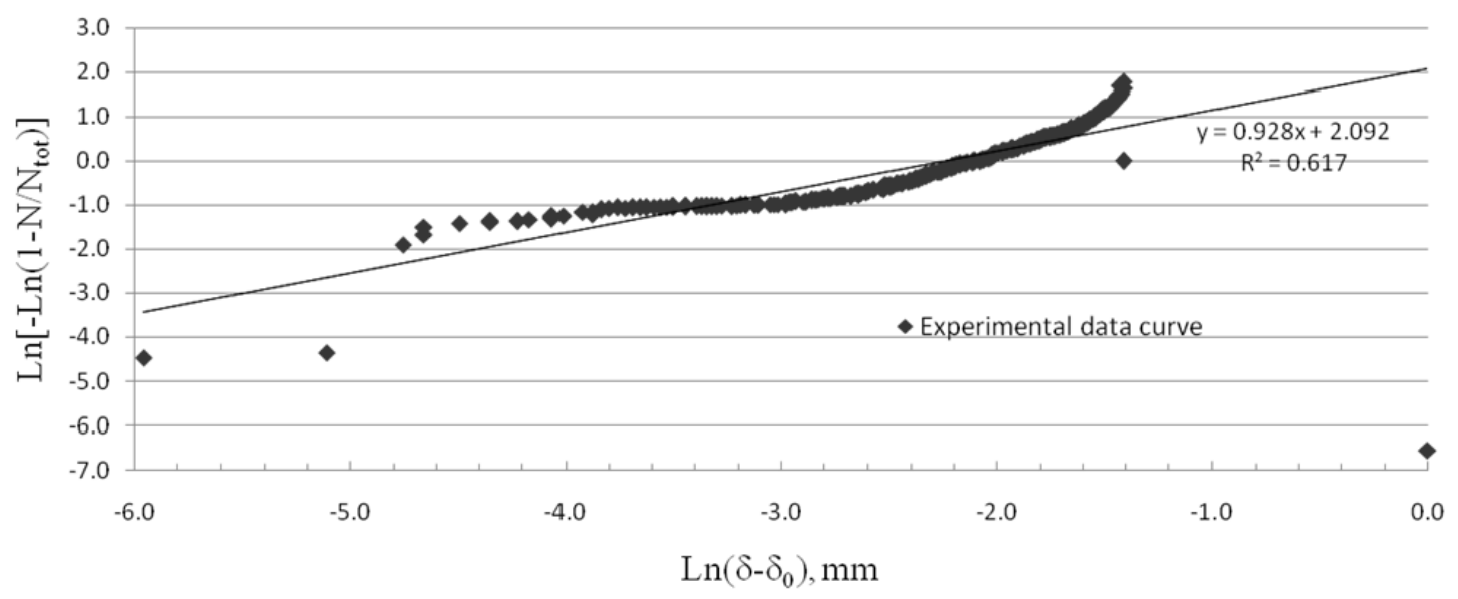

Figure 23 Linear regression fitting curve to determine $m$ and $\theta$ in the Weibull distribution 


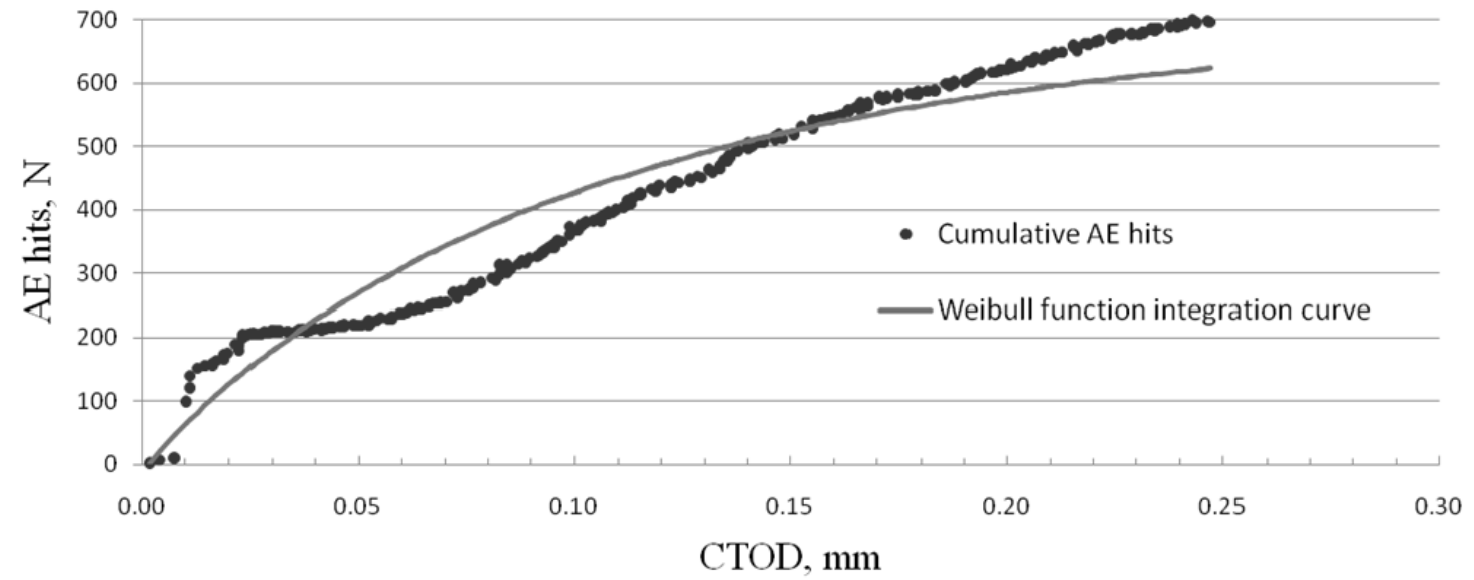

Figure 24 The Weibull function integration curve (the rupture probability function multipling the total hit number) and the cumulative AE hit curve vs. CTOD

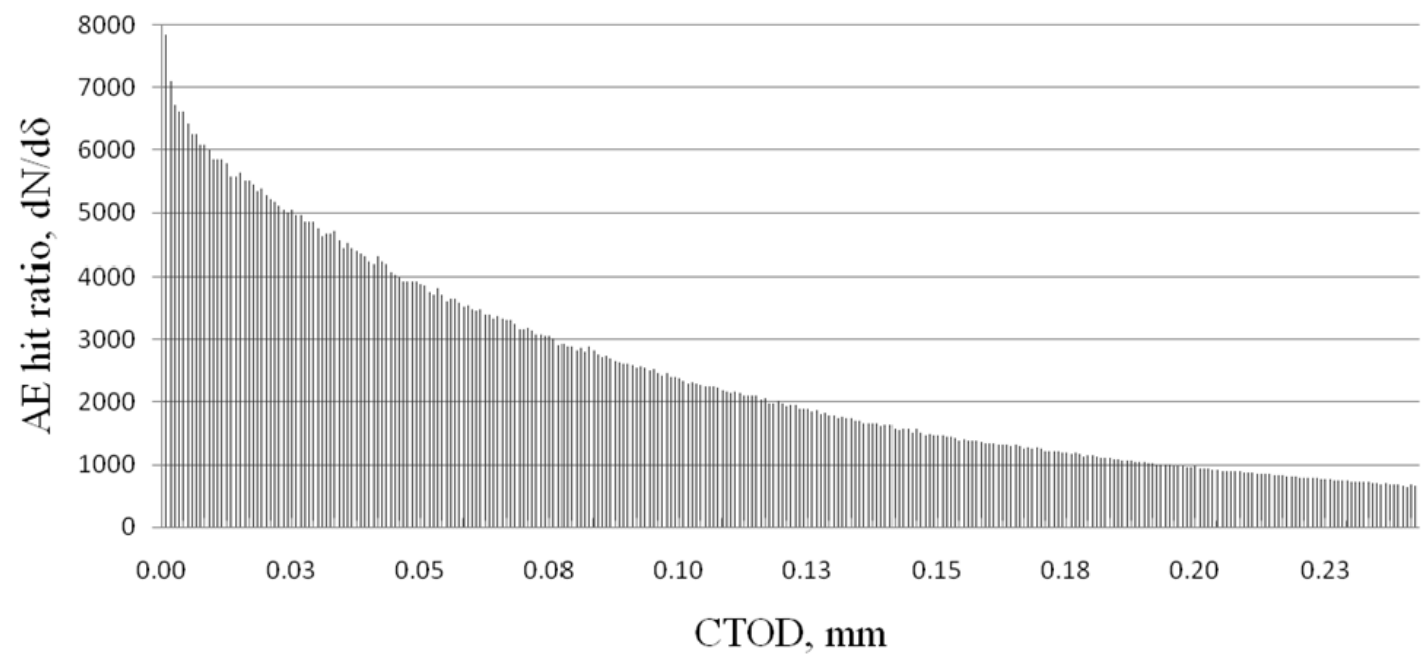

Figure 25 The histogram of the rapture probability density function with the calibrated Weibull distribution vs. CTOD

The detected AE signal data is compared with calculated AE signal data. The mean value of detected $\mathrm{AE}$ hits is 431 and deviation is 181.9; mean value of the calculated AE hits is 434.4 and the deviation is 159.8 . The In Table 7, relative error is calculated, 


$$
R E_{i}=\frac{y_{2, i}-y_{1, i}}{y_{1, i}}
$$

where $y_{1, i}$ is cumulative AE hits from experimental test; $y_{2, i}$ is the calculated AE hits from the calibrated Weibull distribution function.

Standard deviation is calculated from

$$
\sigma=\sqrt{\frac{1}{N} \sum_{i=1}^{N}\left(R E_{i}-\mu\right)^{2}}
$$

where $N$ is the number of samples; $\mu$ is average value of relative error. The result is shown in Table 7, which shows the agreement between experimental data and calculated data.

\begin{tabular}{|c|c|c|c|c|c|c|c|c|c|}
\hline $\begin{array}{l}\text { Time } \\
\text { (Sec) }\end{array}$ & $\begin{array}{c}\text { LOA } \\
\text { D } \\
(\mathbf{k N}) \\
\end{array}$ & $\begin{array}{l}\text { CTOD } \\
(\mathrm{mm})\end{array}$ & $\begin{array}{c}\text { Lab } \\
\text { AE } \\
\text { hits } \\
\end{array}$ & Histogram & $\ln \left(\boldsymbol{\delta}-\boldsymbol{\delta}_{\mathbf{0}}\right)$ & $\ln \left(-\ln \left(1-N / \mathbf{N}_{\text {tot }}\right)\right.$ & $\mathbf{N}_{\delta}$ & $d N / d \delta$ & $\begin{array}{c}\text { AE hit } \\
\text { from } \\
\text { Weibull }\end{array}$ \\
\hline 7.20 & 0.022 & 0.0017 & 1 & 1 & - & -6.55 & 0.00 & - & 0.00 \\
\hline 9.40 & 1.580 & 0.0077 & 9 & 1 & -5.11 & -4.35 & 47.77 & 7095.37 & 47.77 \\
\hline 11.40 & 2.062 & 0.0112 & 120 & 22 & -4.66 & -1.67 & 71.35 & 6620.32 & 71.35 \\
\hline 13.40 & 2.536 & 0.0129 & 152 & 12 & -4.49 & -1.41 & 82.58 & 6424.52 & 82.58 \\
\hline 15.40 & 2.734 & 0.0146 & 157 & 1 & -4.35 & -1.37 & 93.49 & 6246.51 & 93.49 \\
\hline 17.40 & 2.768 & 0.0164 & 160 & 3 & -4.22 & -1.35 & 104.10 & 6082.32 & 104.10 \\
\hline 19.40 & 2.751 & 0.0189 & 166 & 2 & -4.06 & -1.31 & 119.52 & 5856.31 & 119.52 \\
\hline 21.40 & 2.837 & 0.0189 & 174 & 4 & -4.06 & -1.25 & 119.52 & 5856.31 & 119.52 \\
\hline 23.40 & 2.777 & 0.0224 & 180 & 4 & -3.88 & -1.21 & 139.21 & 5584.18 & 139.21 \\
\hline 25.40 & 2.854 & 0.0215 & 190 & 3 & -3.92 & -1.15 & 134.38 & 5649.54 & 134.38 \\
\hline 27.40 & 2.837 & 0.0232 & 203 & 4 & -3.84 & -1.07 & 144.00 & 5520.41 & 144.00 \\
\hline 47.40 & 2.717 & 0.0362 & 211 & 0 & -3.37 & -1.03 & 209.79 & 4706.34 & 209.79 \\
\hline 67.40 & 2.725 & 0.0534 & 226 & 1 & -2.96 & -0.94 & 283.45 & 3885.52 & 283.45 \\
\hline 87.40 & 2.656 & 0.0689 & 254 & 1 & -2.70 & -0.80 & 339.02 & 3305.36 & 339.02 \\
\hline 107.40 & 2.467 & 0.0844 & 312 & 0 & -2.49 & -0.53 & 386.45 & 2829.65 & 386.45 \\
\hline 127.40 & 2.191 & 0.1025 & 379 & 3 & -2.30 & -0.25 & 433.36 & 2373.64 & 433.36 \\
\hline 147.40 & 1.959 & 0.1180 & 434 & 4 & -2.15 & -0.04 & 467.56 & 2049.06 & 467.56 \\
\hline 167.40 & 1.769 & 0.1361 & 487 & 4 & -2.01 & 0.17 & 501.66 & 1731.67 & 501.66 \\
\hline 187.40 & 1.451 & 0.1550 & 540 & 5 & -1.88 & 0.39 & 531.77 & 1456.18 & 531.77 \\
\hline
\end{tabular}

Table 6 Typical test results comparison between AE system and mechanical test 


\begin{tabular}{llllllllll}
\hline 207.40 & 1.348 & 0.1714 & 573 & 3 & -1.77 & 0.53 & 553.92 & 1256.41 & 553.92 \\
227.40 & 1.218 & 0.1860 & 600 & 3 & -1.69 & 0.66 & 571.16 & 1102.55 & 571.16 \\
247.40 & 1.055 & 0.2006 & 632 & 5 & -1.61 & 0.84 & 586.29 & 968.67 & 586.29 \\
267.40 & 0.969 & 0.2179 & 663 & 2 & -1.53 & 1.07 & 601.78 & 832.93 & 601.78 \\
287.40 & 0.917 & 0.2351 & 687 & 2 & -1.46 & 1.36 & 615.10 & 717.13 & 615.10 \\
299.40 & 0.840 & 0.2463 & 701 & 2 & -1.41 & - & 622.75 & 651.06 & 622.75 \\
\hline
\end{tabular}

Table 7 The average value $\mu$ and standard deviation $\sigma$ of relative error

\begin{tabular}{cc}
\hline$\mu$ & $\sigma$ \\
\hline 0.0451 & 0.3246 \\
\hline
\end{tabular}




\subsection{Freeze-thaw concrete test}

The concrete damage under freeze-thaw cycles is under investigation with controlled freeze test. The concrete specimen was prepared. The water/cement ratio $(\mathrm{w} / \mathrm{c})$ is 0.5 to introduce more capillary pores. Table 1 listed the weight ratio of fine and coarse aggregates for the mixture design. The ratio of coarse aggregates to fine aggregates is $60 / 40$.

Five concrete cylinders with the 4 inches diameter and 6 inches height were used as shown in Figure 26. The test is implemented in accordance with the ASTM standard C666: rapid freeze and thaw test. The testing procedure is to place concrete cylinders in freezer with controlled temperature about $0^{\circ} \mathrm{F}$ for 5 hours then move the specimens into $37^{\circ} \mathrm{F}$ water lasting one hour before the next cycle. The acquired $\mathrm{AE}$ data reflected the internal flaw evolution in some extent. However, the background noises should be filtered from with $\mathrm{AE}$ detection system to capture the real $\mathrm{AE}$ fracture signals. Due to the acoustic and electromagnetic noise from the periodic operation of thermostat in the freezer, we plan to use one quiet testing environment. A commercial cooler was substituted for the laboratory freezer and the dry ice was used as cooling agent as shown in the Figure 26. Preliminary freeze-thaw test was conducted and the typical AE signal waveform is shown in Figure 27. This signal was acquired during the first cycle of freezing test. 
Table 8 Aggregate sizes and weight ratios in the mixture design

\begin{tabular}{cccc}
\hline \multirow{2}{*}{ Aggregate Types } & \multicolumn{2}{c}{ Sieve Size } & \multirow{2}{*}{ Weight Ratio (\%) } \\
\cline { 2 - 3 } & Inch & $\mathrm{mm}$ & 27 \\
\hline \multirow{3}{*}{ Coarse Aggregates } & $3 / 8^{\prime \prime}$ & 9.50 & 24 \\
& $\# 4$ & 4.75 & 9 \\
& $\# 8$ & 2.36 & 20 \\
Fine Aggregates & $\# 16$ & 1.18 & 10 \\
& $\# 30$ & 0.60 & 6 \\
& $\# 50$ & 0.30 & 4 \\
\hline
\end{tabular}
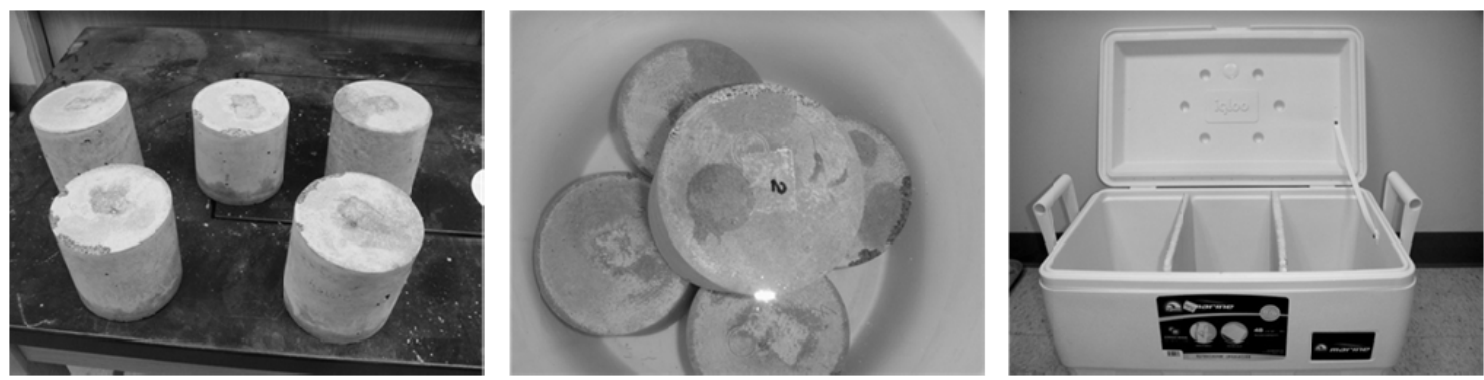

Figure 26 Left shows the specimens; middle shows specimen submerged in the water; right shows the cooler used for freeze-thaw test (by author)

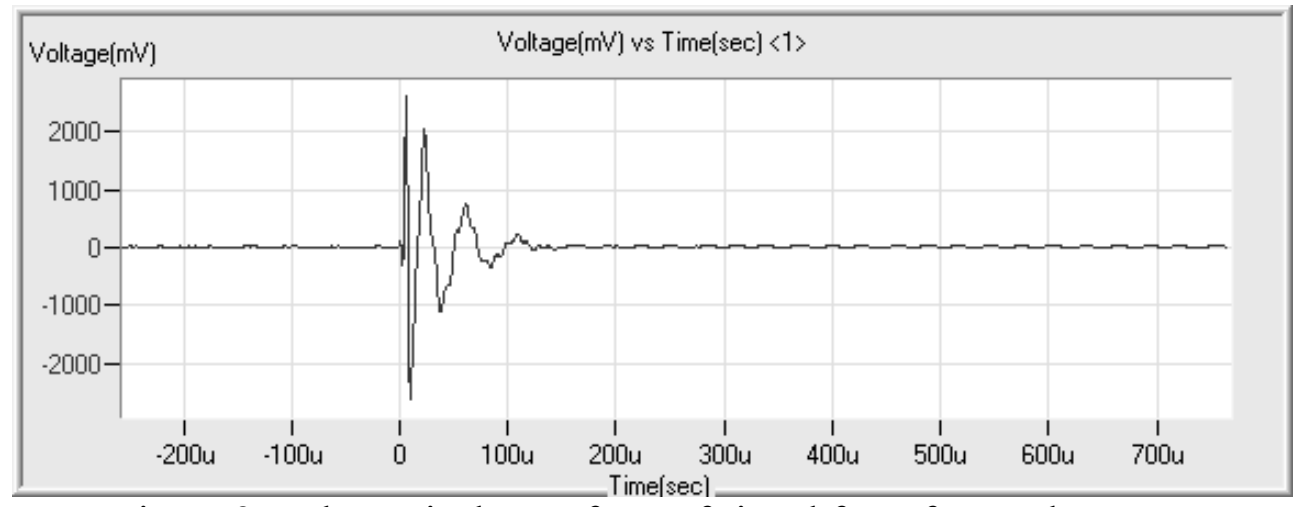

Figure 27 The typical waveform of signal from freeze-thaw test 


\section{Conclusion and future work}

The AE system was setup to detect the concrete damage under mechanical loading and freeze-thaw cycles in this study. The pensile lead test was conducted with different breaking locations. And the captured signals show the signal amplitudes decrease with the $\mathrm{AE}$ wave travel distances. The $\mathrm{AE}$ amplitude from the laboratory test results were compared with the ones from attenuation equation. It showed agreement between them. The SEB tests with concrete beam specimens were conducted with UTM testing system and also under $\mathrm{AE}$ damage detection. The $\mathrm{AE}$ acoustic signals such as accumulative AE hit curves have good correlation with the mechanical loading-CTOD behavior. The statistical analysis was conducted to calibrate the parameters of Weibull distribution for damage probability density. The calibrated damage probability density function has good representation of the cumulative AE hit curve.

In the future study, the beam bending tests will be conducted with ultra high performance concrete (UHPC) specimens and also under the AE damage detection. The damage function of UHPC will be calibrated with detected AE detailed signals. The concrete freeze test with $\mathrm{AE}$ detection will be continued to unveil the detailed damage process under freeze-thaw cycles. 


\section{Reference}

Berkovits, A. and D. Fang (1995). "Study of fatigue crack characteristics by acoustic emission." Engineering Fracture Mechanics 51(3): 401-409.

Bernd Weiler, S. X., Utz Mayer (1997). "Acoustic emission analysis applied to concrete under different loading conditions." Otto graf journal 8: 255-269.

Carpinteri, A. and G. Lacidogna (2007). Earthquakes and acoustic emission.

Carpinteri, A., G. Lacidogna, et al. (2007). "Structural damage diagnosis and life-time assessment by acoustic emission monitoring." Engineering Fracture Mechanics 74(1-2): 273-289.

Chen, B. and J. Liu (2004). "Experimental study on AE characteristics of three-pointbending concrete beams." Cement and Concrete Research 34(3): 391-397.

Choudhury, A. and N. Tandon (2000). "Application of acoustic emission technique for the detection of defects in rolling element bearings." Tribology International 33(1): 39-45.

Farid Uddin, A. K. M., K. Numata, et al. (2004). "Mechanisms of crack propagation due to corrosion of reinforcement in concrete by AE-SiGMA and BEM." Construction and Building Materials 18(3): 181-188.

Granger, S., A. Loukili, et al. (2007). "Experimental characterization of the self-healing of cracks in an ultra high performance cementitious material: Mechanical tests and acoustic emission analysis." Cement and Concrete Research 37(4): 519-527. 
Grosse, C., H. Reinhardt, et al. (1997). "Localization and classification of fracture types in concrete with quantitative acoustic emission measurement techniques." $\underline{\text { NDT \& }}$ E International 30(4): 223-230.

Grosse, C. U. and F. Finck (2006). "Quantitative evaluation of fracture processes in concrete using signal-based acoustic emission techniques." Cement and Concrete Composites 28(4): 330-336.

Grosse, C. U. and M. Ohtsu (2008). Acoustic Emission Testing.

Labuz, J., S. Dai, et al. (1996). "Identifying failure through locations of acoustic emission." Transportation Research Record 1526: 104-111.

Labuz, J. F., S. Cattaneo, et al. (2001). "Acoustic emission at failure in quasi-brittle materials." Construction and Building Materials 15(5-6): 225-233.

Leszek Golaski, P. G., And Kanji Ono (2002). "Diagnostics of reinforced concrete bridges by acoustic emission." Journal of Acoustic Emission 20: 83-98.

Li, W., W. Sun, et al. (2011). "Damage of concrete experiencing flexural fatigue load and closed freeze/thaw cycles simultaneously." Construction and Building Materials 25(5): 2604-2610.

Lockner, D. (1993). "The role of acoustic emission in the study of rock fracture." International Journal of Rock Mechanics and Mining Sciences \& Geomechanics Abstracts 30(7): 883-899.

Morton, T. M., R. M. Harrington, et al. (1973). "Acoustic emissions of fatigue crack growth." Engineering Fracture Mechanics 5(3): 691-692, IN617-IN618, 693-697.

Nair, A. and C. S. Cai (2010). "Acoustic emission monitoring of bridges: Review and case studies." Engineering Structures 32(6): 1704-1714. 
Ohno, K. and M. Ohtsu (2010). "Crack classification in concrete based on acoustic emission." Construction and Building Materials 24(12): 2339-2346.

Ohtsu, M. (1995). "The history and development of acoustic emission in concrete engineering." Magazine of concrete research 48: 321-330.

Ohtsu, M. and H. Watanabe "Quantitative damage estimation of concrete by acoustic emission." Construction and Building Materials 15(5-6): 217-224.

Otsuka, K. and H. Date (2000). "Fracture process zone in concrete tension specimen." Engineering Fracture Mechanics 65(2-3): 111-131.

Pollock, A. A. (1989). "Acoustic Emission Inspection." Metals Handbook 17: 278-294.

Prosser, W. H. (1996). "Advanced AE technique in composite materials research." Journal of Acoustic Emission 14(3-4): S1-S11.

Ranjith, P. G., D. Jasinge, et al. (2008). "A study of the effect of displacement rate and moisture content on the mechanical properties of concrete: Use of acoustic emission." Mechanics of Materials 40(6): 453-469.

Roberts, T. M. and M. Talebzadeh (2003). "Acoustic emission monitoring of fatigue crack propagation." Journal of Constructional Steel Research 59(6): 695-712.

Shield, C. K. (1997). "Comparison of acoustic emission activity in reinforced and prestressed concrete beams under bending." Construction and Building Materials 11(3): 189-194.

Shigeishi, M., S. Colombo, et al. (2001). "Acoustic emission to assess and monitor the integrity of bridges." Construction and Building Materials 15(1): 35-49.

Shiotani, T., D. G. Aggelis, et al. (2007). "Global monitoring of concrete bridge using acoustic emission." Journal of Acoustic Emission 25: 308-315. 
Soulioti, D., N. M. Barkoula, et al. (2009). "Acoustic emission behavior of steel fibre reinforced concrete under bending." Construction and Building Materials 23(12): 3532-3536.

Suzuki, T., H. Ogata, et al. (2010). "Use of acoustic emission and X-ray computed tomography for damage evaluation of freeze-thawed concrete." Construction and Building Materials 24(12): 2347-2352.

Suzuki, T. and M. Ohtsu (2004). "Quantitative damage evaluation of structural concrete by a compression test based on $\mathrm{AE}$ rate process analysis." Construction and Building Materials 18(3): 197-202.

The_engineering_toolbox. "Speed of Sound in some common Solids." from http://www.engineeringtoolbox.com/sound-speed-solids-d_ 713.html.

Uddin, F., M. Shigeishi, et al. (2006). "Fracture Mechanics of Corrosion Cracking in Concrete by Acoustic Emission." Meccanica 41(4): 425-442.

Wei Zhang, C. X., Fanjin Kong (2008). Application of wide band AE sensor in model test of reinforced concrete. 17 th world conference on nondestructive testing. Shanghai.

Weibull, W. A. (1951). "A statistical distribution function of wide applicability." Journal of Applied Mechanics 18: 292-297. 